\title{
WIND-TUNNEL STUDY ON GASEOUS MIXING \\ DUE TO VARIOUS STACK HEIGHTS AND INJECTION RATES \\ ABOVE AN ISOLATED STRUCTURE
}

by

R. N. Meroney

and

B. T. Yang

\author{
Prepared for \\ U.S. Atomic Energy Commission \\ Contract AT (11-1)- 2053 \\ Fallout Studies Branch \\ Division of Biology and Medicine \\ Atomic Energy Commission \\ Fluid Dynamics and Diffusion Laboratory \\ College of Engineering \\ Colorado State University \\ Fort Collins, Colorado 80521
}




\section{ABSTRACT}

WIND-TUNNEL STUDY ON GASEOUS MIXING DUE TO VARIOUS STACK HEIGHTS AND INJECTION RATES ABOVE AN ISOLATED STRUCTURE

This report is a part of a systematic study on gaseous dispersion about an isolated building structure. In order to estimate the maximum ground concentration distribution, the conventional formula are compared with the wind tunnel results. Different stack heights are monitored both by smoke visualization and quantitative concentration measurements. The related parameters such as building orientation, stack height, and exit momentum are discussed. The experiment was conducted in a thick, neutral boundary layer, and a radioactive gas, $\mathrm{Kr}-85$, was used as a tracer for concentration measurements. 
I

I I

III

IV

\begin{abstract}
INTRODUCTION . . . . . . . . . . . . . . 1
TEST PROGRAM AND APPARATUS . . . . . . . . . . 4
\end{abstract}

ANALYSIS AND RESULTS . . . . . . . . . . . 6

3.1 Smoke Visualization . . . . . . . . 6

3.2 Concentration Analysis . . . . . . . 7

a. Zero stack-height . . . . . . . . 7

b. Non-zero stack heights . . . . . 8

3.3 Estimation of Diffusion Distribution about

a Building . . . . . . . . . . . 9

CONCLUSIONS . . . . . . . . . . . . . . 13

BIBLIOGRAPHY . . . . . . . . . . . . . . 14

FIGURES . . . . . . . . . . . . . 15

TABLES . . . . . . . . . . . . . 4 40 


\section{LIST OF FIGURES}

Figure

Page

1 Sketch of the flow field near a structure and the entrainment associated with various release heights... . . . . . . . . . . . . . . 15

2 Block diagram for smoke visualization and $\mathrm{Kr}-85$ concentration measurements .. . . . . . . . . . 16

3 Background (upstream) velocity profile and relative stack-height positions ................ . 17

4-19 Smoke photographs

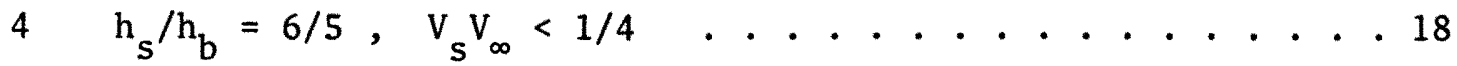

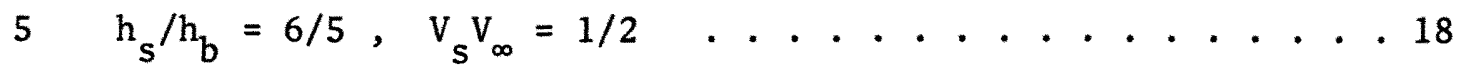

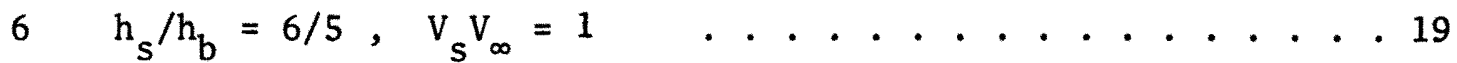

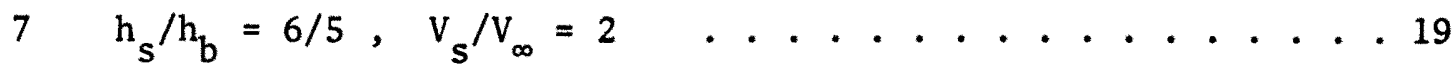

$8 \quad h_{s} / h_{b}=4 / 3, v_{s} / v_{\infty}=1 / 2 \ldots . . . . . . . . . .20$

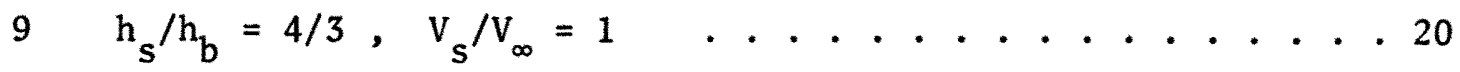

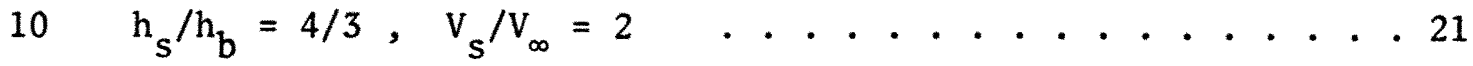

$11 h_{s} / h_{b}=3 / 2, v_{s} / v_{\infty}=1 / 2 \ldots \ldots . . \ldots . . . . . . .21$

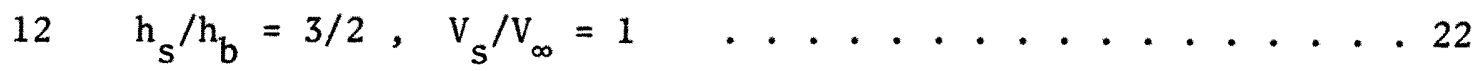

$13 \quad h_{s} / h_{b}=3 / 2, v_{s} / v_{\infty}=2 \ldots . . . \ldots . . . . . . .22$

$14 \quad h_{s} / h_{b}=2 \quad, v_{s} / v_{\infty}=1 / 2 \ldots . . . \ldots . . . . . .23$

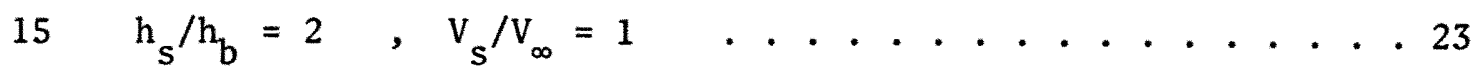

$16 \quad h_{s} / h_{b}=2 \quad, v_{s} / v_{\infty}=2 \quad \ldots . . . \ldots . . . . . . . . .24$

$17 \quad h_{s} / h_{b}=3 \quad, v_{s} / v_{\infty}=1 / 2 \ldots . . . . . . . . . . .24$

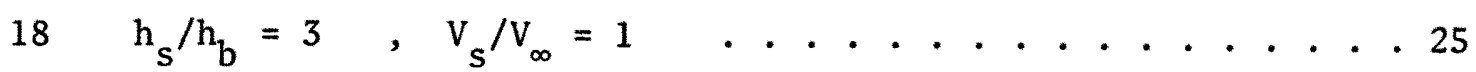

$19 \quad \mathrm{~h}_{\mathrm{s}} / \mathrm{h}_{\mathrm{b}}=3 \quad, \mathrm{v}_{\mathrm{s}} / \mathrm{v}_{\infty}=2 \quad \ldots . . \ldots . . \ldots 25$

20 Visible smoke bounderies for $V_{s} / V_{\infty}=1 / 2$. . . . . . . . 26

21 Visible smoke boundaries for $v_{s} / v_{\infty}=1 \quad$. . . . . . . 27

22 Visible smoke boundaries for $v_{s} / v_{\infty}=2$. . . . . . . 28 
23 Ground concentration for zero stack heights for $\mathrm{V}_{\mathrm{s}} / \mathrm{V}_{\infty}=1 / 2,1 / 4$. . . . . . . . . . . . . . . . . . . . . . 29

24 Ground concentration for $\theta=0^{\circ}, V_{s} / V_{\infty}=1 / 2$, non-zero stack heights ..... . . . . . . . . . 30

25 Ground concentration for $\theta=0^{\circ}, V_{s} / V_{\infty}=1$, non-zero stack heights ...... ............ 31

26 Ground concentration for $\theta=0^{\circ}, V_{s} / V_{\infty}=2$, non-zero stack heights ..... ........... 32

27 Ground concentration for $\theta=45^{\circ}, V_{s} / V_{\infty}=1 / 2$, non-zero stack heights ................. . 33

28 Ground concentration for $\theta=45^{\circ}, v_{s} / V_{\infty}=1$, non-zero stack heights .................. . 34

29 Ground concentration for $\theta=45^{\circ}, V_{s} / V_{\infty}=2$, non-zero stack heights ...... . . . . . . . . . 35

30 Various options for entrainment estimation . . . . . . 36

31 Dispersion improvement due to increased stack heights and exit velocities . . . . . . . . . . . . 37

32 Distances of maximum concentration for various stack heights and exit velocities, $\theta^{0}=0^{\circ} . . . . . .4 . . .38$

33 Distances of maximum concentration for various stack heights and exit velocities, $\theta=45^{\circ}$. . . . . . . . . . 39 


\section{LIST OF TABLES}

Table

$\underline{\text { Page }}$

A

Conversion of $v_{s} / v_{\infty}$ to $v_{s} / v_{h}$. . . . . . . . . . . 40

B

Ground concentration $\left(\frac{L^{2} \times V_{\infty}}{Q}\right), \theta=0^{\circ}$..... 41

C

Ground concentration $\left(\frac{\mathrm{L}^{2} \times \mathrm{V}_{\infty}}{\mathrm{Q}}\right), \theta=45^{\circ} \ldots . . .+42$ 


\section{INTRODUCTION}

One of the principal problems in air-quality control is the prediction of the fluid motions which disperse gaseous products in the atmosphere. To meet the recent need for control of exhausted gases, a quick and reliable estimation of the entrainment phenomenon behind building structures under a variety of conditions is urgent. A few semiempirical formulas have been developed to serve these purposes. But due to the complex gaseous mixing mechanism in a turbulent wake most conventional formulae have proven inaccurate (Yang and Meroney, 1970). An analytic solution is not to be expected, since the flow field near an object, where the non-linear interaction between the separation zone and inertially-generated turbulence exists, has yet to be solved.

The introduction of a building into a background flow which has a logarithmic mean-velocity profile, homogeneous turbulence, and uniform pressure causes a change in the velocity and pressure fields. Figure 1 shows the principal characteristics of the flow field near a sharp-edged building oriented with one face normal to the wind stream. The region of aerodynamic distortion has three zones: the displacement zone, the wake, and the cavity (Chang, 1966 and Plate, 1971). The displacement zone is the upstream result of the presence of the obstacle. The wake and cavity result from the phenomenon of separation. The increased turbulence and secondary motions in the cavity and wake radically alter the dispersion rate of effluents entrained into their field of influence.

A short review has been presented by Yang and Meroney (1970) on the short-stack effects with which many urban industries are concerned. For an isolated building, a stack height (from the ground) of $21 / 2$ times the building height and exit velocity of ratio $V_{s} / V_{\infty}$ of unity is 
recommended (Smith, 1968). However due to pressures from other restrictions and special circumstances (i.e., architect design, social pressure on hugh chimney, interference on aviation, etc.), alterative injection rates and stack heights are often sought. The entrainment effect upon maximum ground concentration is closely related to the plume rise. The plume rise and its prediction for an isolated stack has been reviewed by Briggs (1970), but the presence of a nearby building structure may cause immediate entrainment, fumigation, and higher ground concentration levels.

Often it is felt a field study is required to understand the gaseous dispersion for a specific topography, thermal stratification, and building geometry. Such a field study usually requires a large detecting grid system and many support personne1. The degrees of freedom for the wind speeds, directions and thermal stratification conditions are almost infinite. To systematically survey a set of alternative configurations is usually an exhaustive process. A wind-tunnel model study has been designed to help survey the specific mixing mechanism in a more controllable environment. Under proper similarity assumptions, the results from a model study should offer a picture of the desirability of various design alternatives.

This experiment is a part of a set of systematic wind-tunnel studies on the gaseous dispersion due to different stack heights, different building geometries, different thermal stratifications, various exit momentums and plume densities (Symes and Meroney, 1970) (Yang and Meroney, 1970). The basic modeling criteria can be found in a previous report (Yang and Meroney, 1970). 
In this specific experiment, the ground-level concentration distribution behind a cubical structure with different stack release heights is studied. The entrainment effect due to various exit velocities (or efflux velocities), wind directions and building orientations is also examined. 
II. TEST PROGRAM AND APPARATUS

This experiment was conducted in the $2 \mathrm{~m} \times 2 \mathrm{~m}$ Meteorological Wind Tunnel in the Fluid Dynamic and Diffusion Laboratory at Colorado State University. A detailed description of the wind tunnel and the test apparatus can be found in a previous report (Yang and Meroney, 1970). General block diagrams for the smoke visualization technique and the concentration measurement are shown in Figure 2 .

In the wind tunnel experiments, a turbulent boundary layer can be roughly defined by specifying the free-stream velocity $V_{\infty}$, friction velocity $v_{*}$, and roughness height $z_{0}$. In many situations, the ratio of exit velocity to the "local" mean velocity is desired. This is to emphasize the immediate momentum interaction between the plume and shear layer. In the boundary layer, the plume will encounter different momentum at different heights. The authors propose that when exit momentum is high (say $V_{s} / V_{\infty} \geq 1$ ), the proper scaling factor should be $\mathrm{V}_{\infty}$ or more appropriately, $\mathrm{V}_{*}$. The plume will not be affected by the mean wind velocity throughout its trajectory. However, for small exit velocities, the appropriate scaling factor should be $V_{h}$; since the plume will be expected to stay at the same approximate height as the stack. Figure 3 displays the background flow profile and the relative positions of different (height) stacks. Table A provides a conversion of $v_{s} / V_{\infty}$ to $v_{s} / V_{h}$. 
1. Boundary Layer inickne,s $\sim 65 \mathrm{~cm}$

2. Free Stream Velocity $\left(\mathrm{V}_{\infty}\right): 2 \mathrm{~m} / \mathrm{sec}$

3. Thermal Stratification: Neutral

4. Floor Roughness: $z_{0} \simeq 0.01 \mathrm{~cm}$ $V^{*} \simeq 0.144 \mathrm{~m} / \mathrm{sec}$

5. Building Shape: $15 \mathrm{~cm} \times 15 \mathrm{~cm} \times 15 \mathrm{~cm}$ cube

6. Stack I.D.: $1 / 4$ inches $\sim 0.635 \mathrm{~cm}$

7. Stack 0.D.: $3 / 8$ inches $\sim 0.95 \mathrm{~cm}$

8. Smoke-generating material: Titanium tetrachloride $\mathrm{TiCl}_{4}$

9. Tracer Gas: Krypton-85 and air mixture (source concentration = $4.2 \mu$ curies/c.c.)

10. Experiments performed:

(i) Stack Height and Exit Momentum:

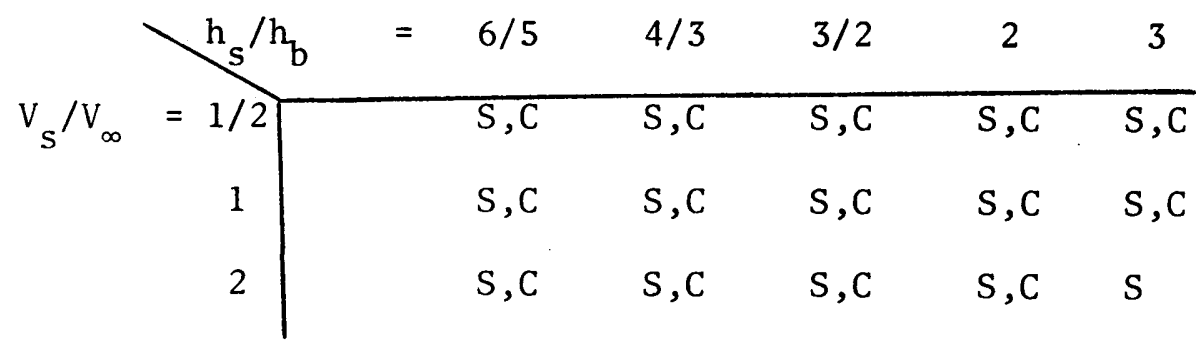

$\mathrm{h}_{\mathrm{S}}$ : stack height (measured from the ground)

$\mathrm{h}_{\mathrm{b}}$ : building height $(=15 \mathrm{~cm})$

$\mathrm{V}_{\mathrm{S}}$ : exit velocity

$\mathrm{S}$ : smoke visualization conducted

$\mathrm{C}$ : concentration measurement conducted

(ii) Zero-stack-height: $\mathrm{V}_{\mathrm{s}} / \mathrm{V}_{\infty}=1 / 4$ and $\mathrm{V}_{\mathrm{s}} / \mathrm{V}_{\infty}=1 / 2$ 
Figure 20,21 , and 22 plot the visible smoke boundary lines. Frequently the vaguely visible plume outlined area is interpreted as the locus of points approximately $10 \%$ of centerline concentration. Note that when $h_{s} / h_{b}<2$ plumes essentially overlap. This is due to the mechanical turbulence and the gradually increasing wind speed with height in the boundary layer.

\subsection{Concentration Analysis}

Concentration data were obtained at ground level center-1ine downstream to almost 53 times the building height. Table $B$ and $C$ summarize al1 the concentration data taken along the center-line downwind.

a. Zero stack-height:

Two exit velocity ratios are examined, i.e., $V_{s} / V_{\infty}=1 / 4$

and $V_{s} / V_{\infty}=1 / 2$. Using the non-dimensional $\mathrm{K}$-factor $\left(\mathrm{K}=\frac{\mathrm{L}^{2} \mathrm{~V}_{\infty} \mathrm{X}}{\mathrm{Q}}\right)$, one finds the concentration distributions are almost identical (Figure 23). The -0.6 slope (found by Yang and Meroney, 1970) gives a very good estimation in this zero stack-height (exit at the very top of a building) situation. This indicates that in case the plume does not have enough momentum to penetrate the cavity zone (which is characterized by negative pressure, large eddies and high turbulent intensities), the concentration distributions are almost independent of the exit velocities. The ground-level concentrations thus show a similar, characteristic distribution.

The dispersion rate does not display any significant tendency to recover from a -0.6 slope to a situation where the atmospheric turbulence dominates plume behavior such that the dispersion rate ranges from -1.3 to -1.8 . 
Previous studies of dispersion in the wind tunnel shear layer reproduces characteristic atmospheric behavior for neutral and stratified flows, and for ground and elevated releases (Chaudhry and Meroney, 1969). The delay of the expected far-downstrean assymptotic behavior for the isolated structure may result from a laterally restraining motion set up by the strong horseshoe shaped voxtex which wraps itself around the structure ai ground level (Thwaites, 1960).

Curves II and IV plotted in Figure 23 are the empirical correlations found by Yang and Meroney (1970) which describes ground concentrations in the vicinity of a leaking model structure.

b. Non-zero stack heights:

A first glance at the ground concentration record (Figure 24 through 26) indicates that even a short stack does reduce the concentration at the ground level. The distances to maximum ground concentrations also increase with increases in $h_{s} / h_{b}$ and $v_{s} / V_{\infty}$. When $h_{s} / h_{b}=2$ (i.e., the stack height measured from the ground is twice the building height) and $V_{S} / V_{\infty}=1$, the ground concentration can practically be regarded as zero in the measured distance $\left(\sim 53 \mathrm{~h}_{\mathrm{b}}\right)$.

Figure 27 through 29 plot $h_{s} / h_{b}, V_{s} / V_{\infty}$ combinations but with the building rotated $45^{\circ} \quad\left(\theta=45^{\circ}\right)$. One finds the ground concentration is slightly greater than when $\theta=0^{\circ}$.

This more critical pollution angle is caused by a change in cavity shape due to wind building orientation. The $\left(\theta=45^{\circ}\right)$ cavity zone is about $11 / 2$ times the length of that generated by $\theta=0^{\circ}$ orientation. In the larger cavity zone, an extended opportunity for greater entrainment occurs. Aggravated entrainment at specific wind orientation is 
frequently observed over more complex models (Meroney, Cermak and Chaudhry, 1969).

As cited in Chapter I, higher exit velocities tend to produce the same effects as a higher stack; however, the trade off is not one to one. Both elevate the imaginary diffusion source to a higher level, but higher exit velocities may produce a complex interaction between a turbulent exit jet and approaching wind. The two effects are not additive due to the non-linear characteristics of fluid motion. One must also consider the economics associated with the fact that power required generally goes as velocity cubed.

3.3 Estimation of Diffusion Distribution about a Building:

A number of empirical formulae have been suggested to predict the amount of plume dilution which occurs once it is entrained into the building cavity. These range from extremely conservative to very optimistic.

Culkowski (1969) suggested that a practical conservative estimate for diffusion downwind of a building would be to assume a ground-1evel source and to recognize that the resulting ground level concentration distribution is an upper boundary of all other maximum ground concentrations. This method may over-estimate ground concentration by a factor of twelve for releases into the cavity region, and may over-estimate the case for above cavity releases by a factor of seventy. Such conservatism hardly seems necessary or economical.

Diffusion in the turbulent cavity-wake region of a building has been studied both in the field and wind tunnel with increasing interest during the past ten years. Many formulae for the prediction of downstream concentration distributions have been proposed in the light of 
these studies and Barry (1964) provides a summary of the more popular ones. Meroney and Yang (1970) have also recently reviewed results for the building entrainment problem. In addition they present data for plume entrainment by simple sharp edged structures in neutral and stratified shear flows. Basically all formulas reduce to the form $X / Q=1 / \mathrm{CAV}_{\infty}$ where the constant $\mathrm{c}$ may vary from $1 / 2$ to 2 . Gifford (1960) combined this equation with the Gaussian Plume formula and suggested $x / Q=1 /\left(\pi \sigma_{y} \sigma_{z}+c A\right) V_{\infty}$ as an estimate of the downwind concentration from an extended area source.

For calculating 100 meters beyond a building Yansky, Markee, and Richter (1965) proposed $\frac{X}{Q}=\frac{1}{\pi V_{\infty}\left(\sigma_{y}{ }^{2}+\frac{A}{\pi c}\right)^{1 / 2}\left(\sigma_{z}{ }^{2}+\frac{A}{\pi c}\right)} 1 / 2$

This latter formulation was proposed to adjust for the incomplete mixing across the cavity cross-section.

Surveys taken of cross sections of model plumes suggest it is incorrect to assume the plume is dispersed evenly across the cavity for an elevated plume. In addition $c$ is not a good criteria for plumes only partially entrained by the building cavity. The value of $c$ measured for buildings of rounded geometry will vary from those suggested for sharp edged configurations since the flow separation about a cylinder results in a cavity region of less width than an equivalent cross-section rectangular structure.

In a semiempirical approach, Halitsky (1965) utilized available wind tunnel test data on jet arial velocity decay and jet diameter growth and a qualitative appreciation of the presence of intense mixing in the wake region to predict ground concentrations. Although his model is apparently the only effort which actually considers the 
detailed dynamics of short-stack building-wake interaction it appears overly conservative. A comparison between these model results and the suggested formulations shows an overprediction of concentration by as much as one order of magnitude.

Figure 30 compares the order of plume ground concentrations recommended by the various techniques above. The orders of prediction of the methods of Gifford and Yansky, et. al. appear essentially the same. The improvement of even a modest exhaust velocity and stackheight combination $\mathrm{V}_{\mathrm{s}} / \mathrm{V}_{\infty}=1.0, \mathrm{~h}_{\mathrm{s}} / \mathrm{h}_{\mathrm{b}}=2.0$ appears significant, i.e., a dilution factor of 50. As discussed previously herein the high wind tunnel concentrations at $x / L$ distances of 20 to 60 are disconcerting. This may or may not be a characteristic of diffusion behind isolated structures in atmospheric shear 1 ayers.

The improvement of initial plume dispersal by even modest increases in stack height or exhaust velocity will be important in the design of future industrial and nuclear facilities. A ten fold improvement over the assumption of direct entrainment (i.e. $K \simeq 2.0$ ) may easily be justified for even modest stack velocity ratio combinations. Figure 31 displays the fractional reduction of maximum ground concentration through the addition of a short stack with increased exhaust velocity. As might be expected stack heights which are greater than 2.0-2.5 times the near buildings, appear to eliminate aerodynamic downwash. A simple rule of thumb might be $\frac{K_{\max }}{K_{o}}=\left(\frac{0.02}{\left(h_{s} / h_{b}\right)-0.98}+0.01\right) \frac{V_{\infty}}{V_{s}}$ by assuming $K_{0}-2.0$ (see Fig. 31). It should be observed that once initial entrainment is avoided greater plume rise may be expected by increasing the plume temperature than by increasing the exhaust 
velocity for a given dollar expended. Power is generally expected to go as the velocity cubed.

The shaded area in Fig. 31 is calculated by using the following formulae: (S1ade, 1968, pp. 200)

$$
x_{\max }=\frac{\sigma_{z}}{\sigma_{y}} \frac{2 Q}{\pi h^{2} \mathrm{eV}_{\infty}}
$$

(In a neutral case, $\sigma_{z} / \sigma_{y} \simeq 0.5$ and $\left.\Delta h=1.5\left(V_{s} / V_{\infty}\right) h_{b}\right)$

Therefore, if we assume $K_{0}=2.0$, the formulae reads

$\frac{K_{\max }}{K_{0}} \simeq \frac{A}{\pi e\left(h_{s}+1.5 V_{s} / V_{\infty} h_{b}\right)^{2}}$

where $\pi=3.14, \quad \mathrm{e}=2.718 \ldots$

Figure 32 and 33 plot the distances of maximum concentration for different stack heights and exit velocities. The maximum concentration points seem to go exponentially with increased stack heights which is similar to the situation when no building is present. 


\section{CONCLUSIONS:}

This research was undertaken to ascertain the influence of a simple cubical structure on pollutants released from short stacks at varying exhaust velocities.

On the basis of the experimental measurements reported herein, the following comments can be made:

1) Moderate increases in stack height or exhaust velocity may improve dilution before ground interception by tenfold over the levels expected for complete entrainment.

2) For $h_{s} / h_{b} \leq 1.5$; high exhaust velocities cannot prevent some immediate downwash; however, concentrations are still markedly reduced.

3) As the stack height increases, the effect of building entrainment decreases. Exhaust velocities, for stack height ratios greater than $h_{s} / h_{b}=2.0$, apparently need only be high enough to avoid downwash behind the stack itself.

4) Building orientation apparently aggravates entrainment even for a simple cubical structure; however, the effect is not a major consideration here (For more complicated building complexes the influences may be more significant.)

5) The Gaussian plume growth formulae such as the Pasquil1-Gifford relations may over predict concentrations in the building vicinity and underpredict levels at distances further downstream $(x / L \geq 20)$ (This delayed dispersion may be a characteristic of only isolated structures in shear layers.) 
BIBLIOGRAPHY

Barry, P. L., "Estimation of Downwind Concentration of Airborne Effluents Discharged in the Neighborhood of Buildings. Canadian Report, AECL-2043. July 1964.

Briggs, G. A., Plume Rise, AEC Critical Review Series, USAEC, Division of Technical Information, 1969.

Chang, S. C., "Velocity Distributions in the Separated Flow Behind a Wedge-Shaped Model Hil1," unpublished M. S. thesis, Colorado State University, 1966.

Chandhry, F. H. and Meroney, R. N., "Turbulent Diffusion is a Stably Stratified Shear Layer." Colorado Technical Report CER69-70FHCRNM12, 1969.

Culkowski, W. M., "Estimating the Effect of Buildings on Plumes from Short Stacks," Nuclear Safety, vol. 8, No. 3, 1967, pp. 237-285.

Gifford, F. A., Jr. "Atmospheric Dispersion," Nuclear Safety, vo1. 8, No. 3, 1960 .

Halitsky, J., "Estimation of Stack Height Required to Limit Contamination of Building Air Intakes" J. of Industrial Hygiene, March 1965.

Meroney, R. N., Cermak, J. E. and Chaudhry, F. H., "Wind-Tunne1 Model Study of Shoreham Nuclear Power Station, Unit I, Long Island Lighting Company," Part I and Part II, FDDL Technical Report, CSU, 1969.

Plate, E. J., Aerodynamic Characteristics of Atmospheric Boundary Layers, AEC Critical Review Series, USAEC, Div. of Tech. Information, 1971.

Slade, P. H., editor, Meteorology and Atomic Energy - 1968, USAEC, Div. ot Tech. Information, 1968.

Smith, M., editor, Recommended Guide for the Prediction of the Dispersion of Airborne tffiuents, ASME, 1968.

Symes, C. and Meroney, R. N., "Cone Frustrums in a Shear Layer," FDDL Technical Report, CSU, CER70-71CRS-RNM-11, 1970.

Thwaites, B. editor, Incompressible Aerodynamics, 1960, 0xford Press, pp. 551-553.

Yang, B. T. and Meroney, R. N., "Gaseous Dispersion Into Stratified Building Wakes," FDDL Technical Report, CSU, CER70-71BTY-RNM-8, August 1970 .

Yanskey, G. R., Markee, Jr., Z. H., Richter, A. P., "Climatography of the National Reactor Testing Station," Technical Report ID 0-12048, Air Resources Field Research office National Reactor Testing Station, Idaho Falls, Idaho, 1965. 
Boundary of wake
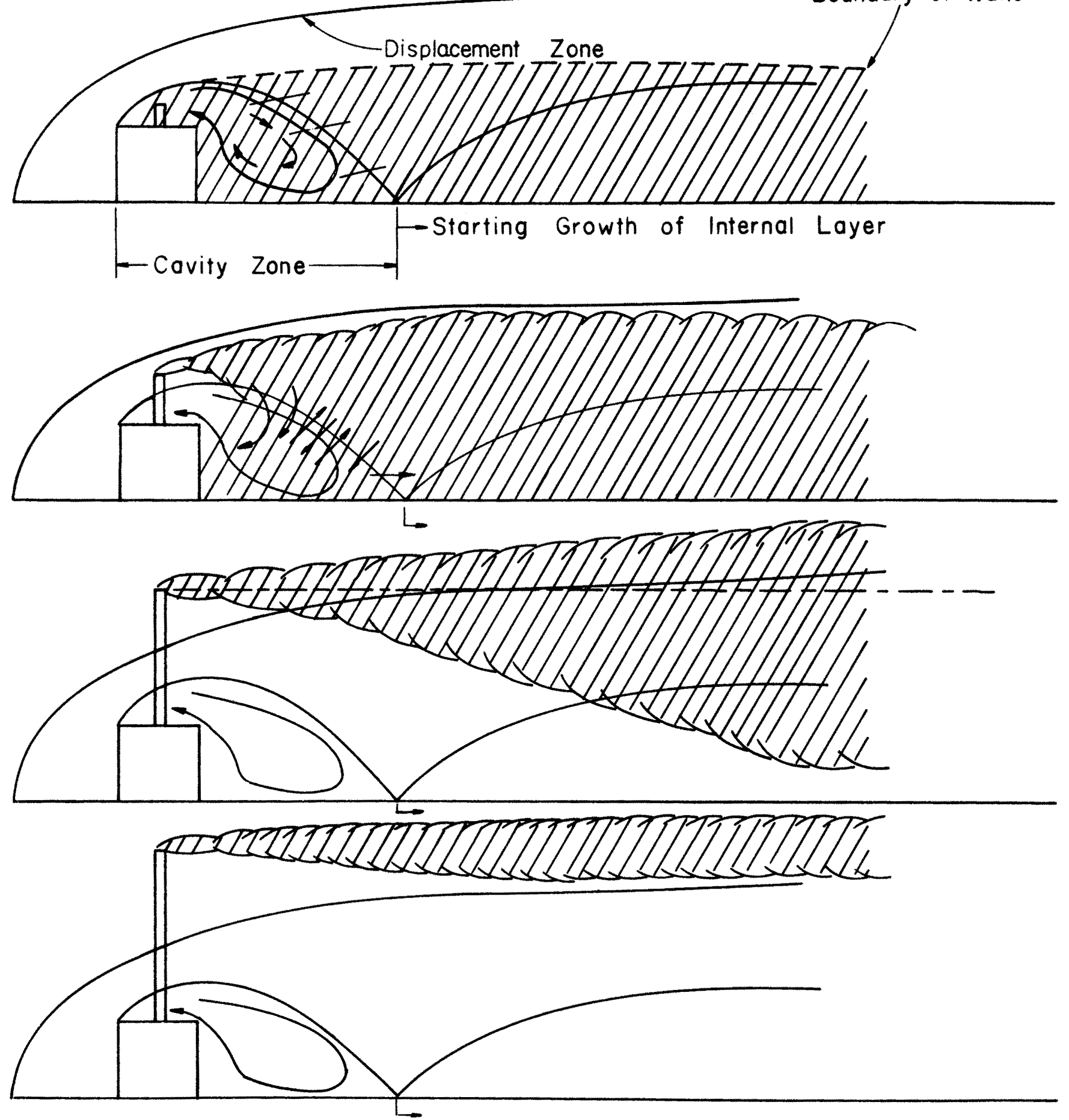

Fig. 1 Sketch of the flow field near a structure and the entrainment associated with various release heights. 


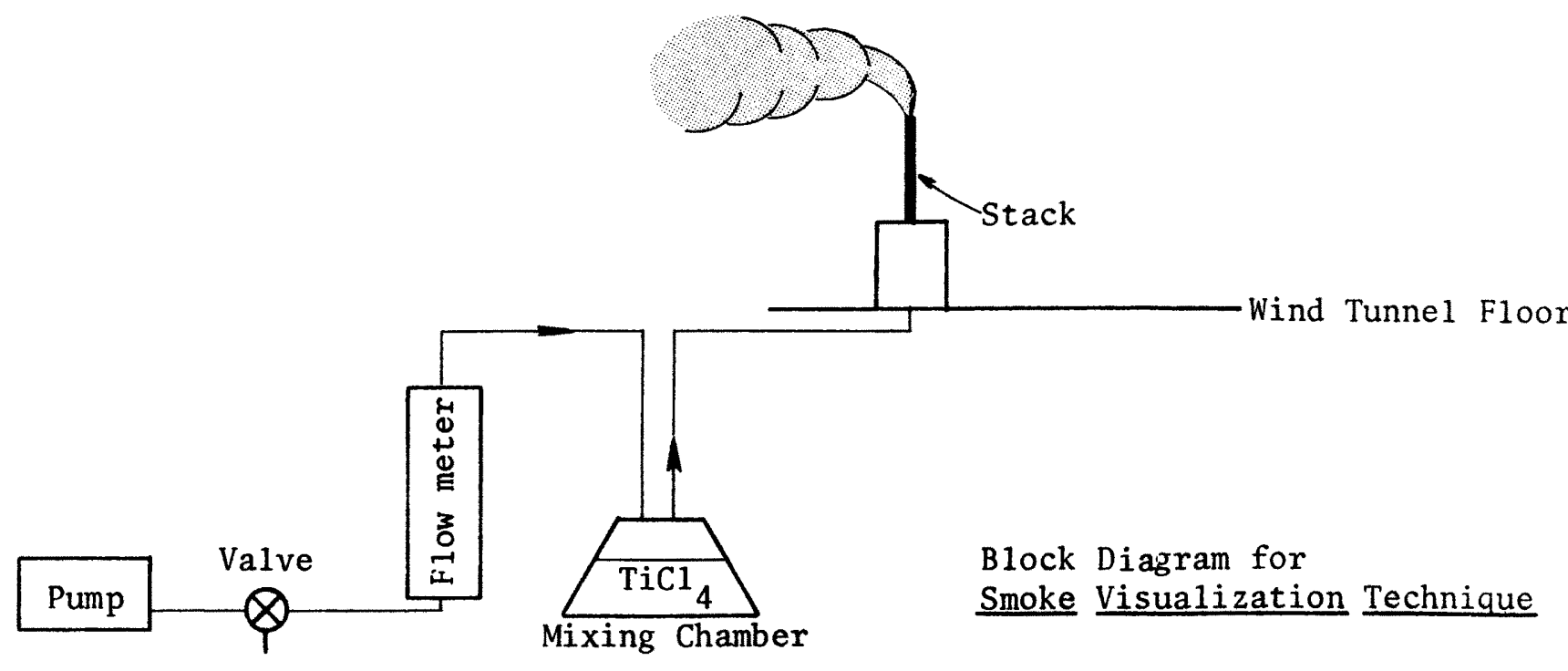

Exhausted
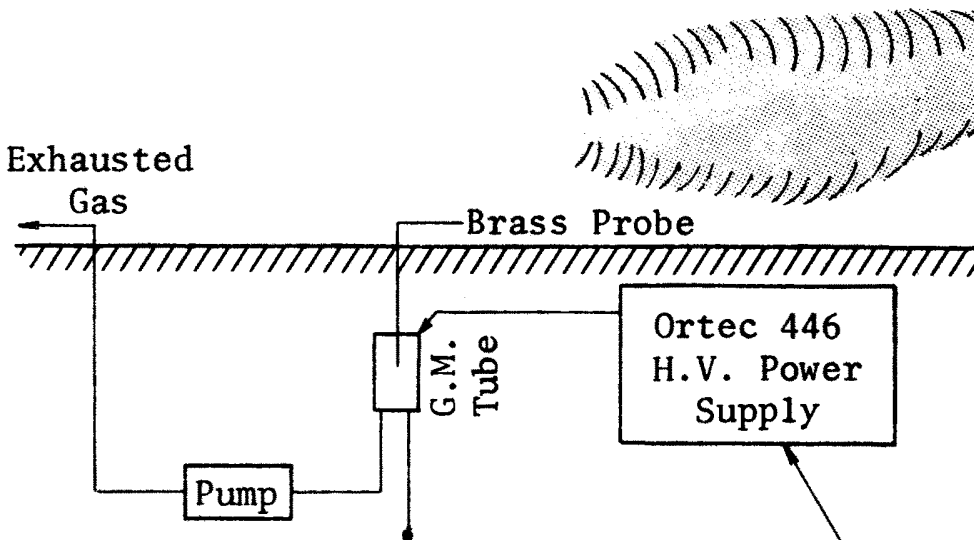

\section{Ortec 446 \\ H.V. Power \\ Supply}

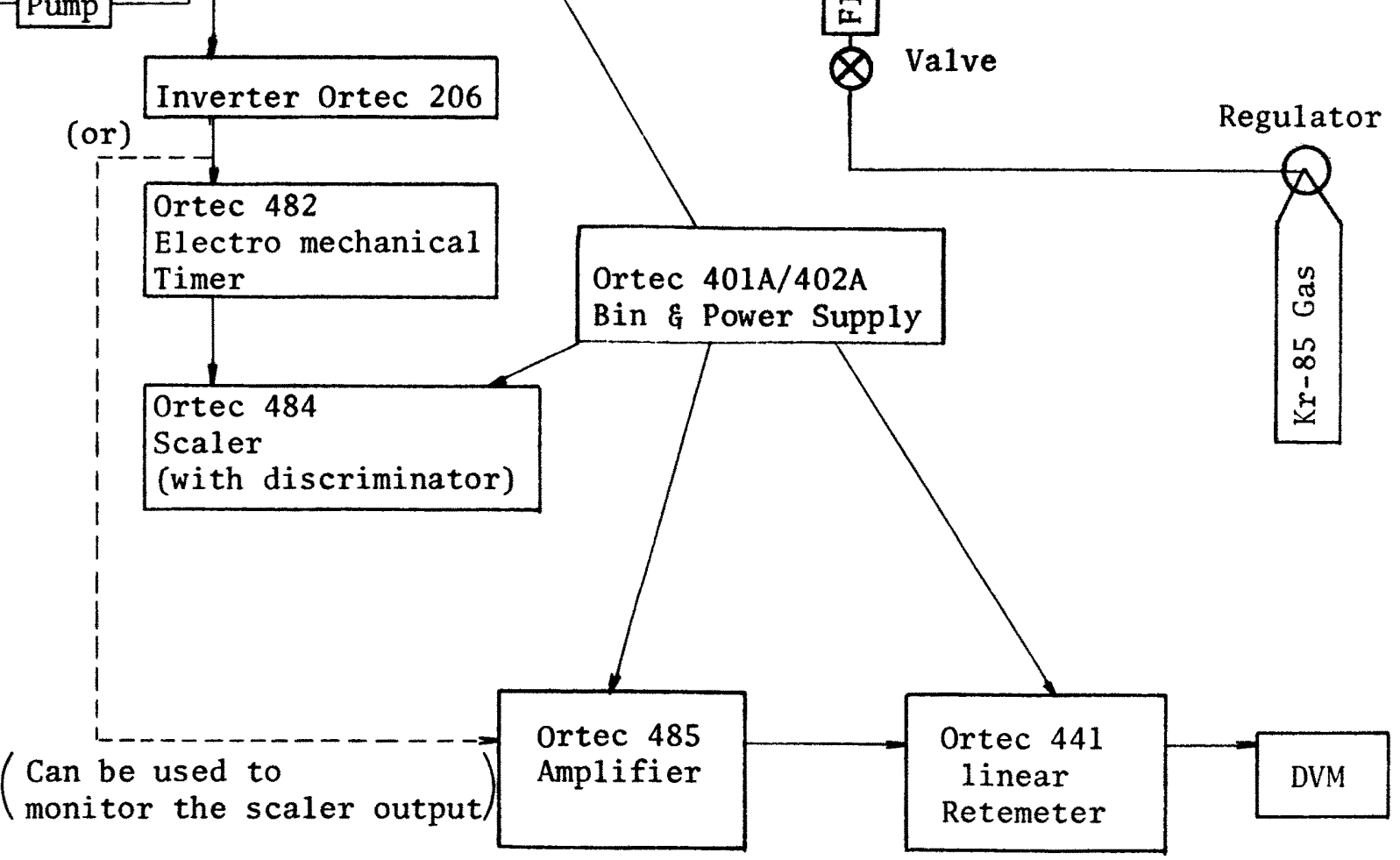

Fig. 2 Block Diagram for Smoke Visualization and $\mathrm{Kr}-85$ Concentration Measurements 


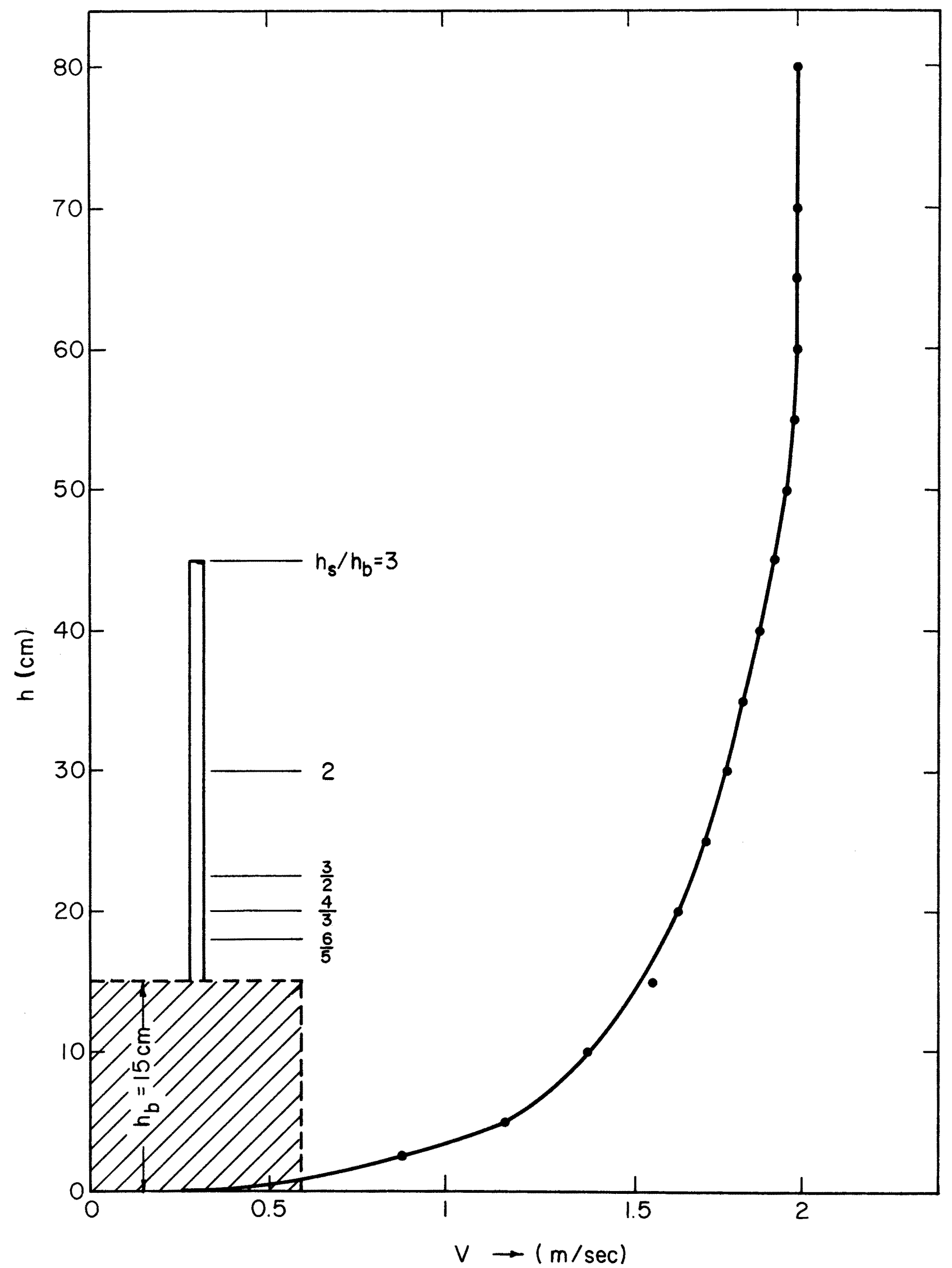

Fig. 3 Background (upstream) velocity profile \& relative stack-heigh positions 


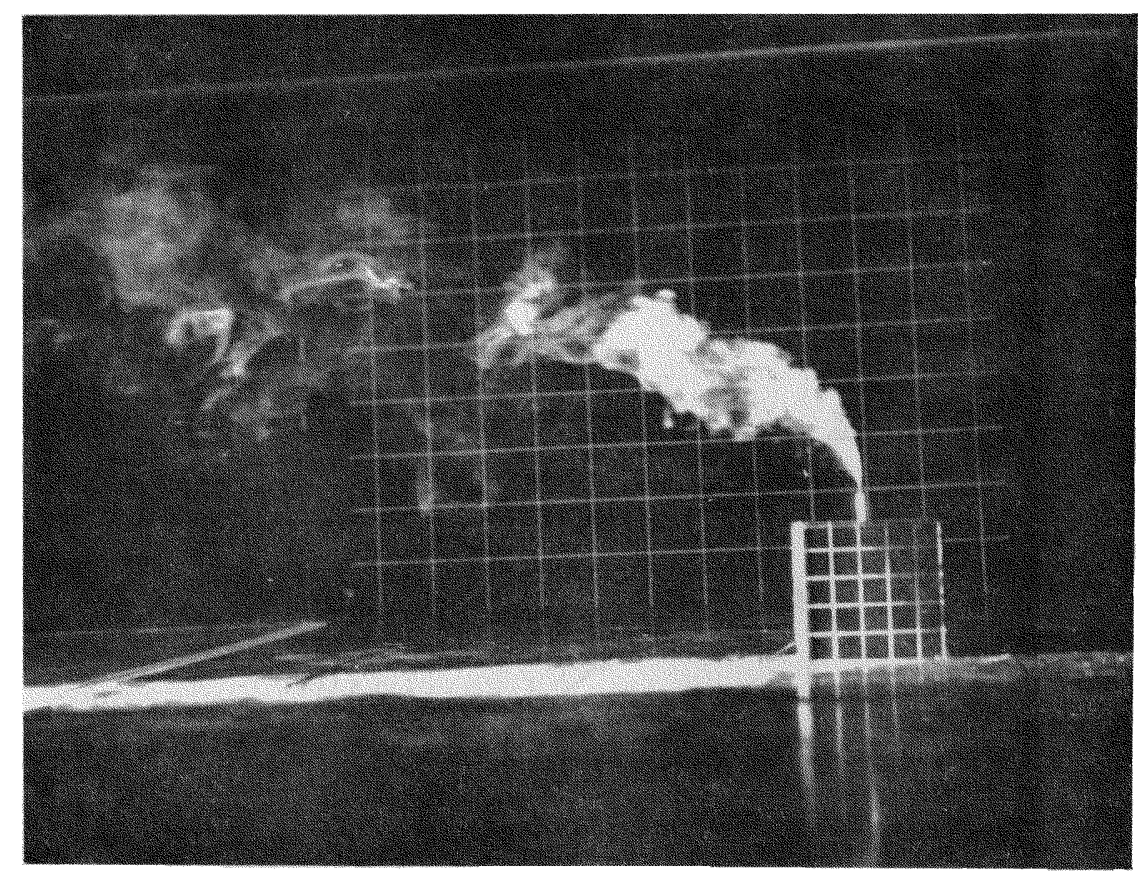

Fig. $4 \quad h_{s} / h_{b}=6 / 5, \quad v_{s} / v_{\infty}<1 / 4$

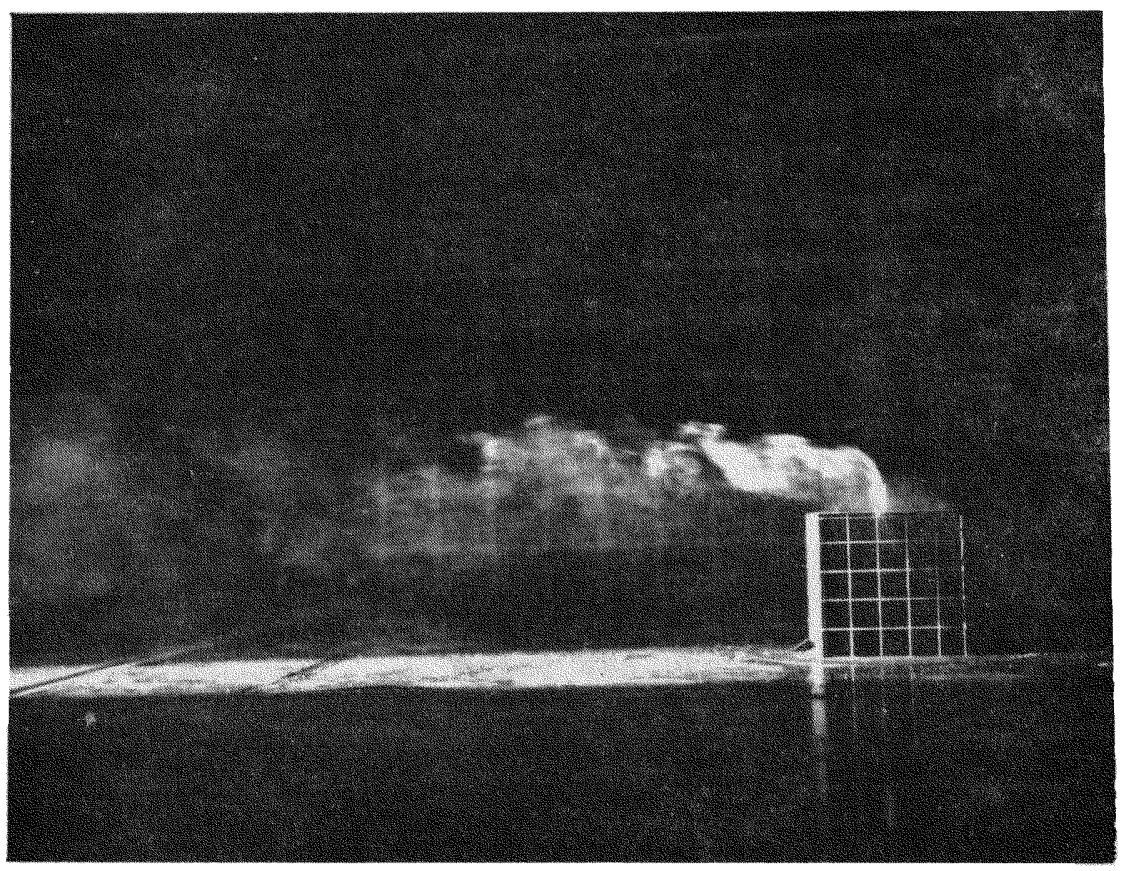

Fig. $5 \quad \mathrm{~h}_{\mathrm{s}} / \mathrm{h}_{\mathrm{b}}=6 / 5, \quad \mathrm{v}_{\mathrm{s}} / \mathrm{V}_{\infty}=1 / 2$ 


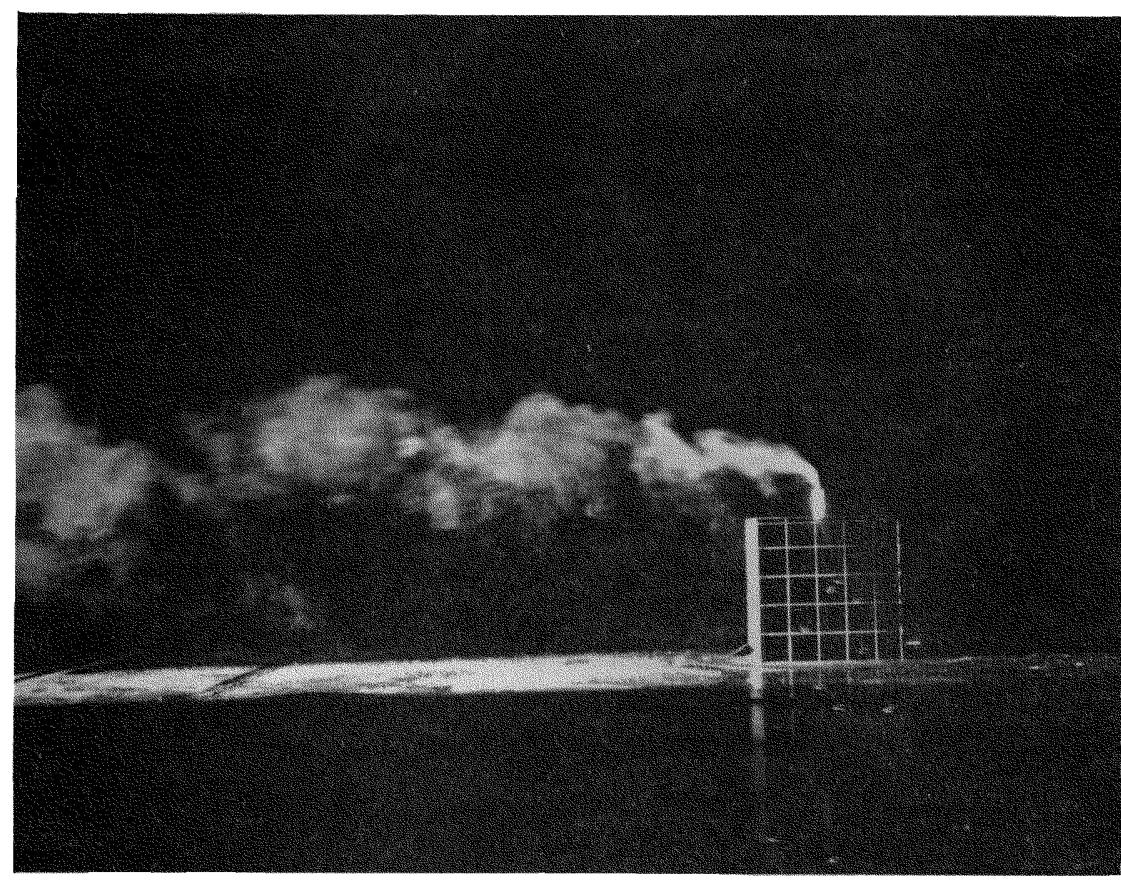

Fig. $6 \quad h_{s} / h_{b}=6 / 5, \quad V_{s} / V_{\infty}=1$

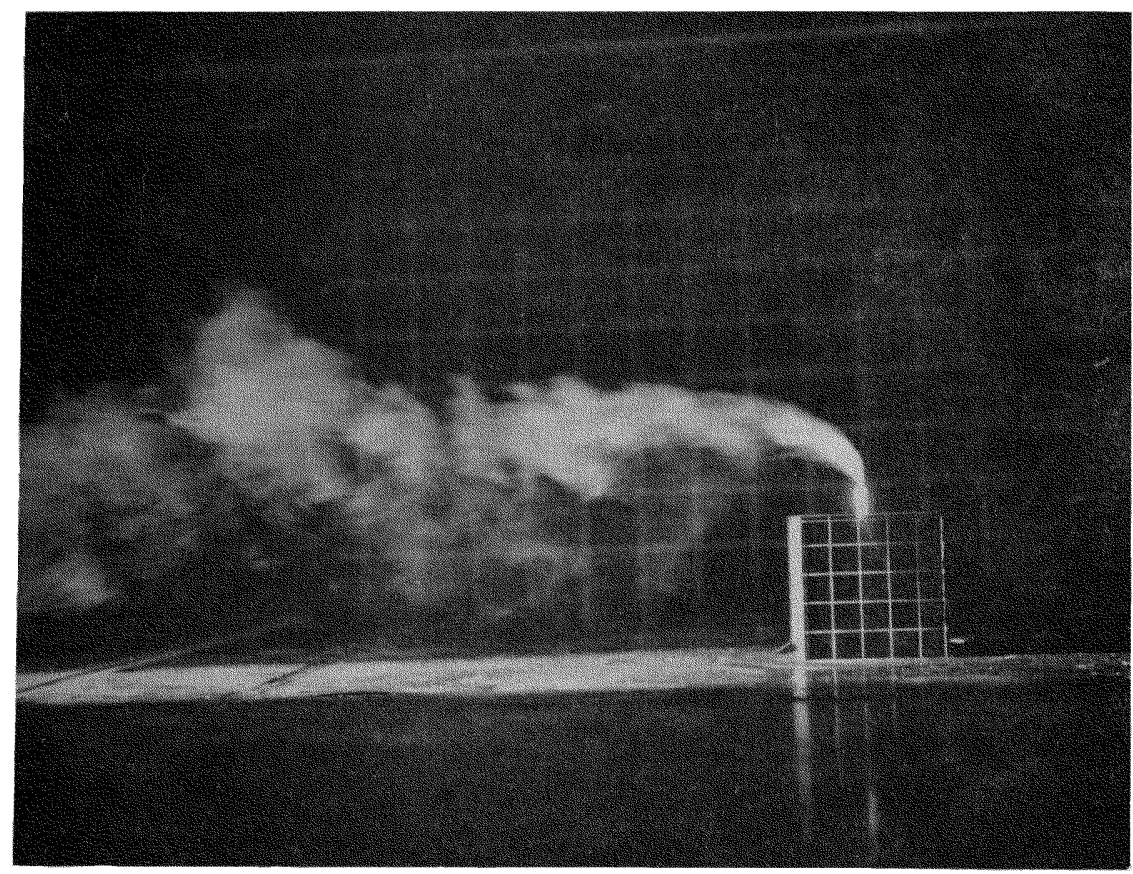

Fig. $7 \quad h_{s} / h_{b}=6 / 5, \quad v_{s} / V_{\infty}=2$ 


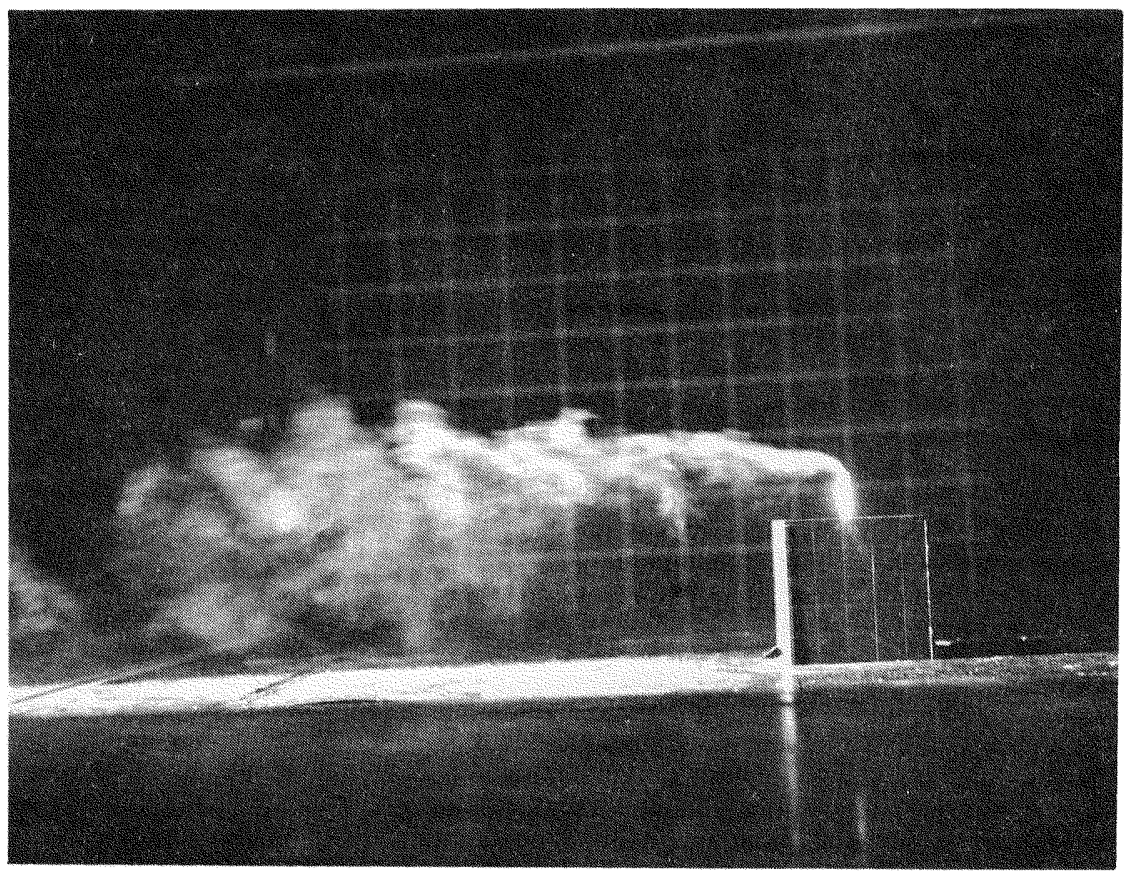

Fig. $8 \quad h_{s} / h_{b}=4 / 3, \quad V_{s} / V_{\infty}=1 / 2$

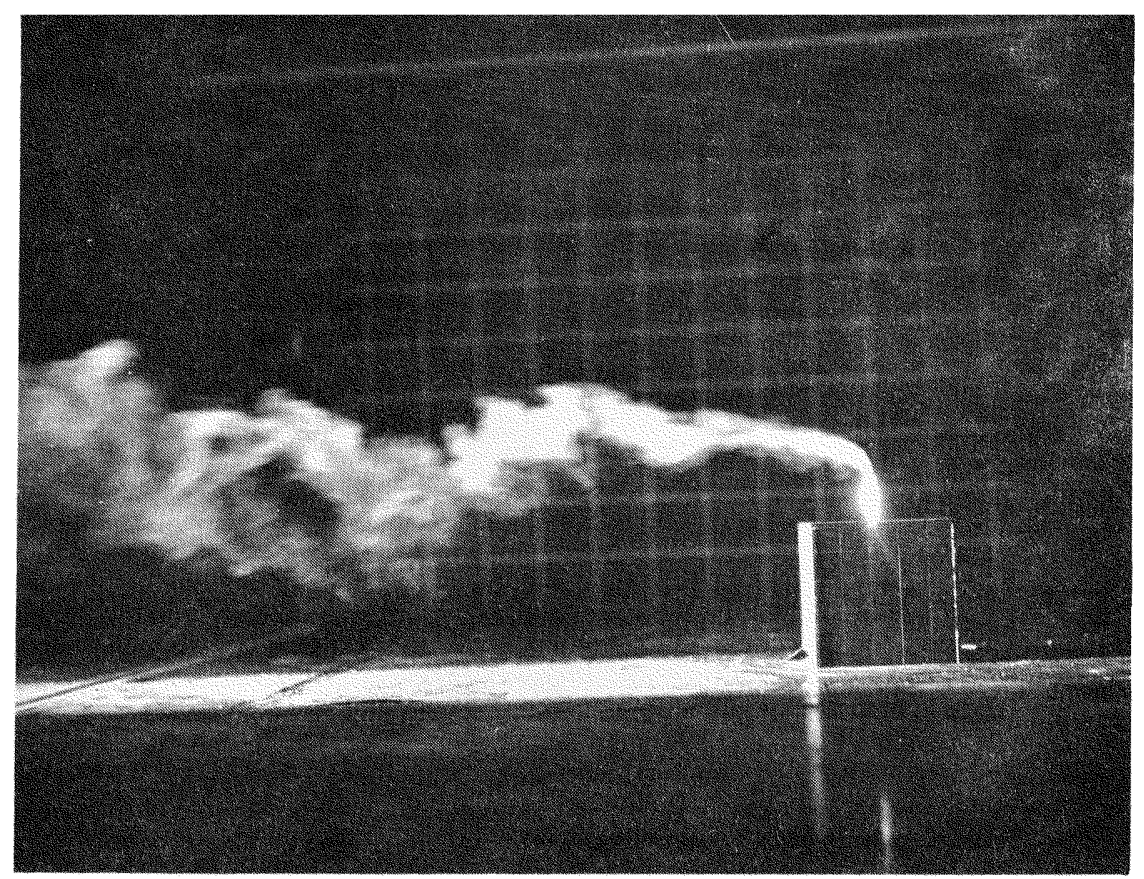

Fig. $9 \quad h_{s} / h_{b}=4 / 3, \quad V_{s} / V_{\infty}=1$ 


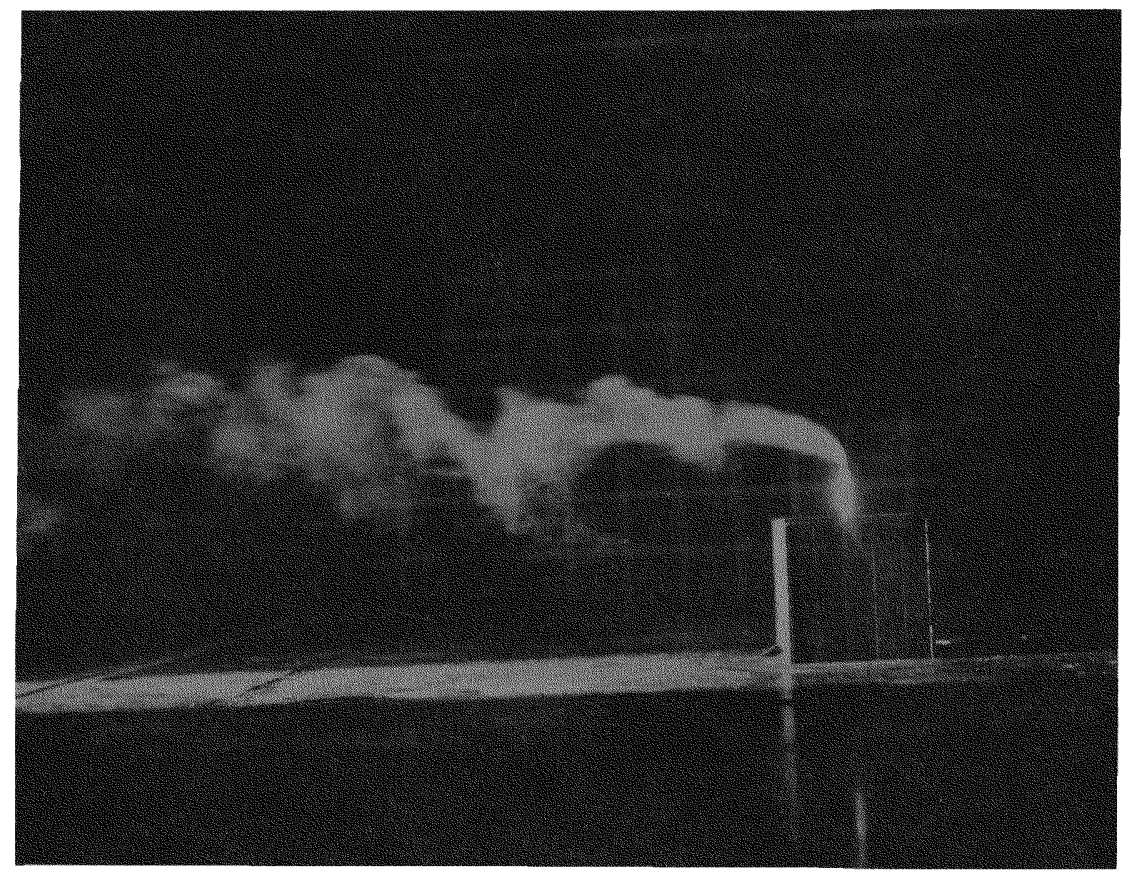

Fig. $10 \quad h_{s} / h_{b}=4 / 3, \quad v_{s} / V_{\infty}=2$

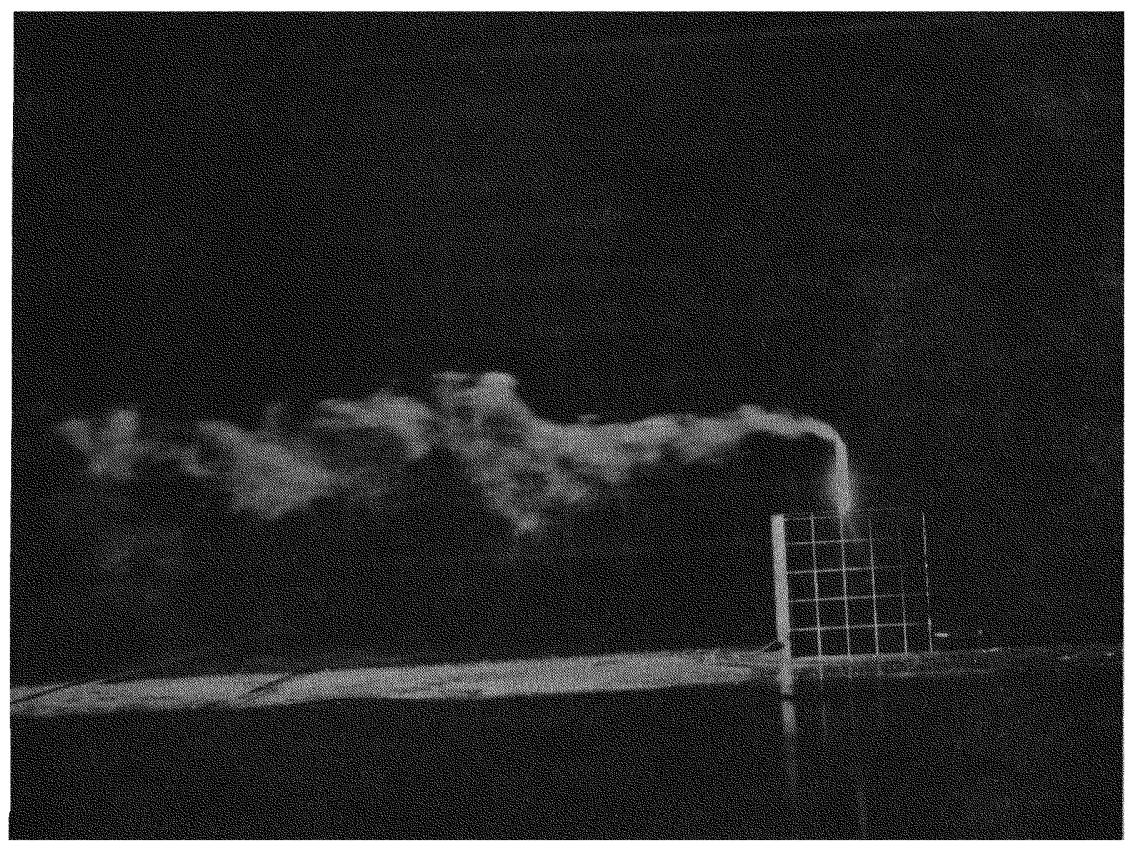

Fig. $11 \quad h_{s} / h_{b}=3 / 2, \quad v_{s} / V_{\infty}=1 / 2$ 


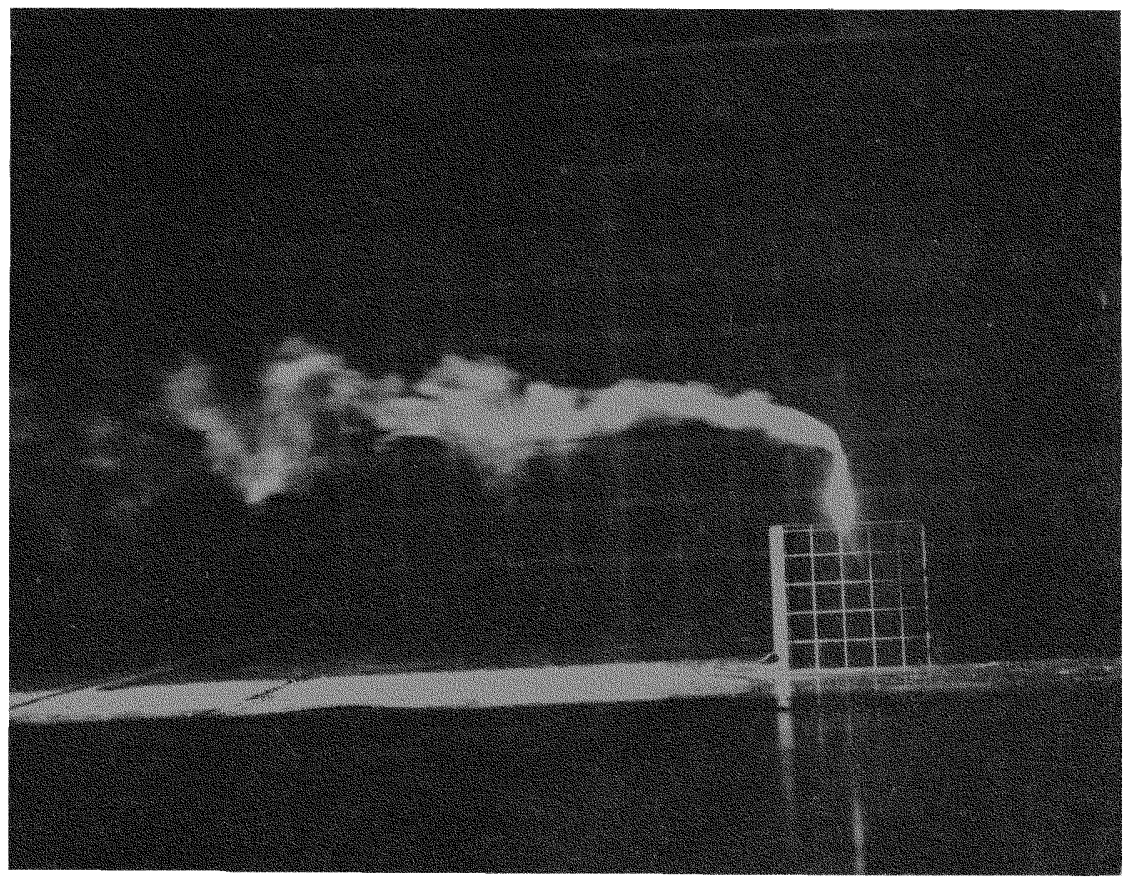

Fig. $12 \quad h_{s} / h_{b}=3 / 2, \quad v_{s} / v_{\infty}=1$

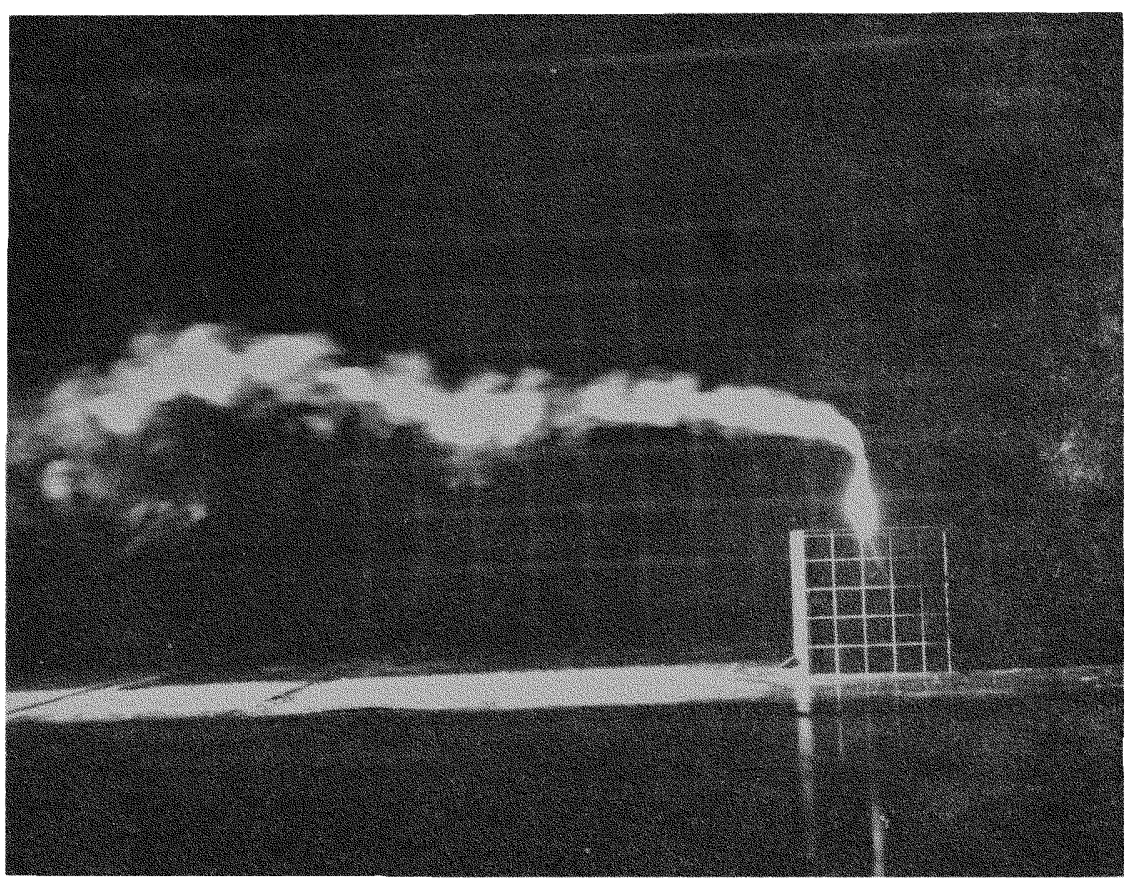

Fig. $13 \quad h_{s} / h_{b}=3 / 2, \quad V_{s} / V_{\infty}=2$ 


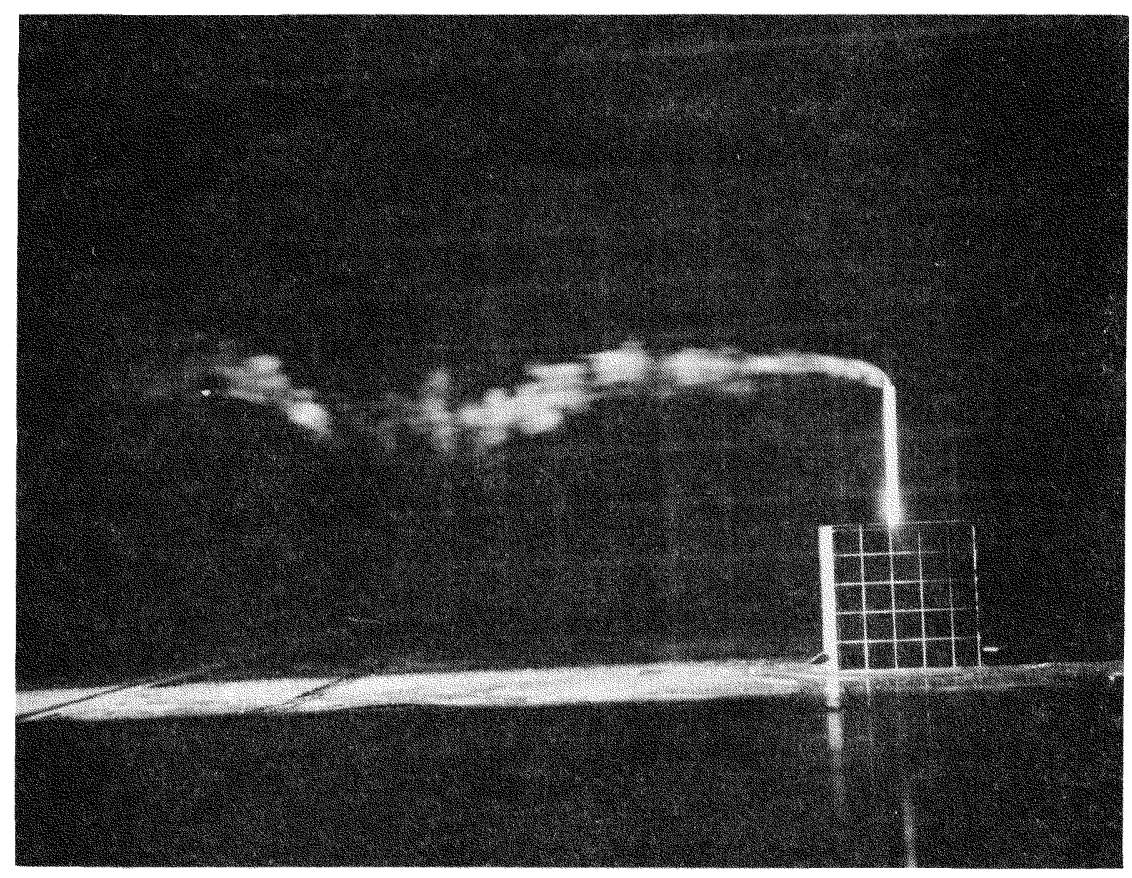

Fig. $14 \quad h_{s} / h_{b}=2, \quad V_{s} / V_{\infty}=1 / 2$

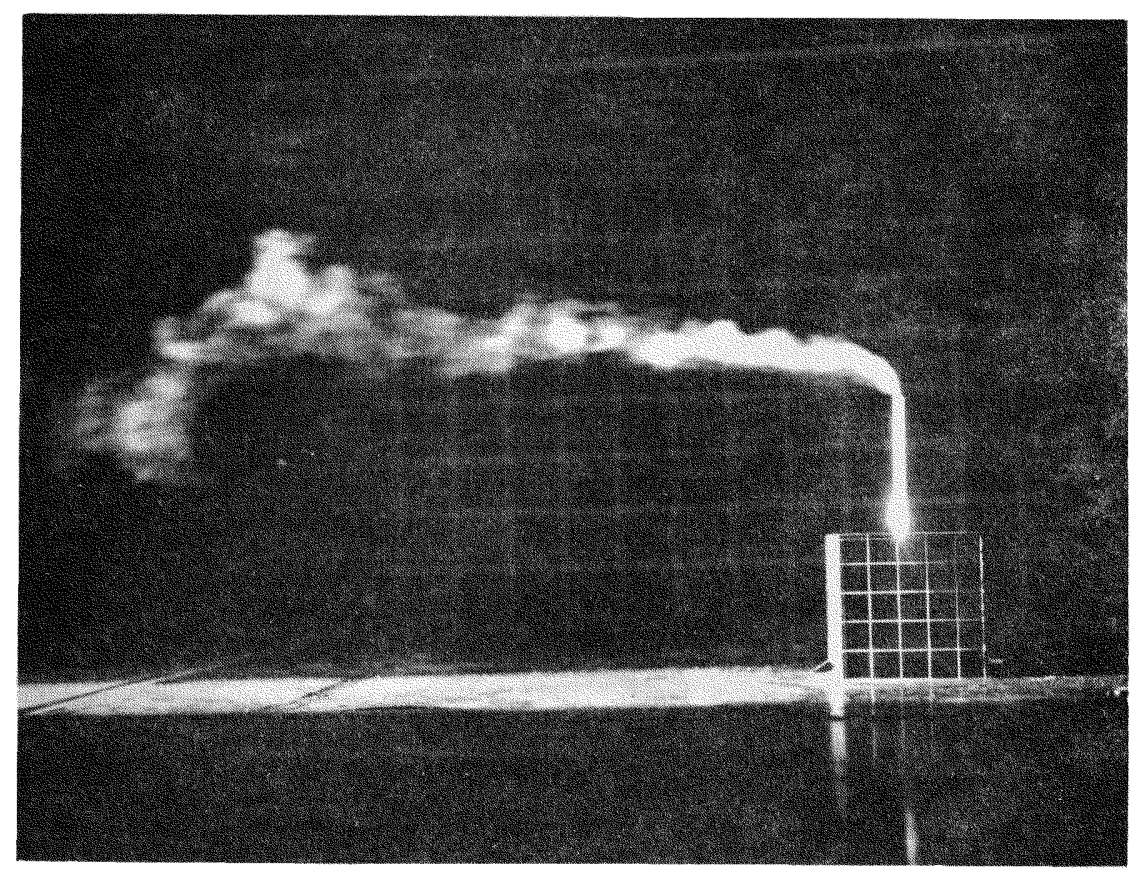

Fig. $15 \quad h_{s} / h_{b}=2, \quad v_{s} / V_{\infty}=1$ 


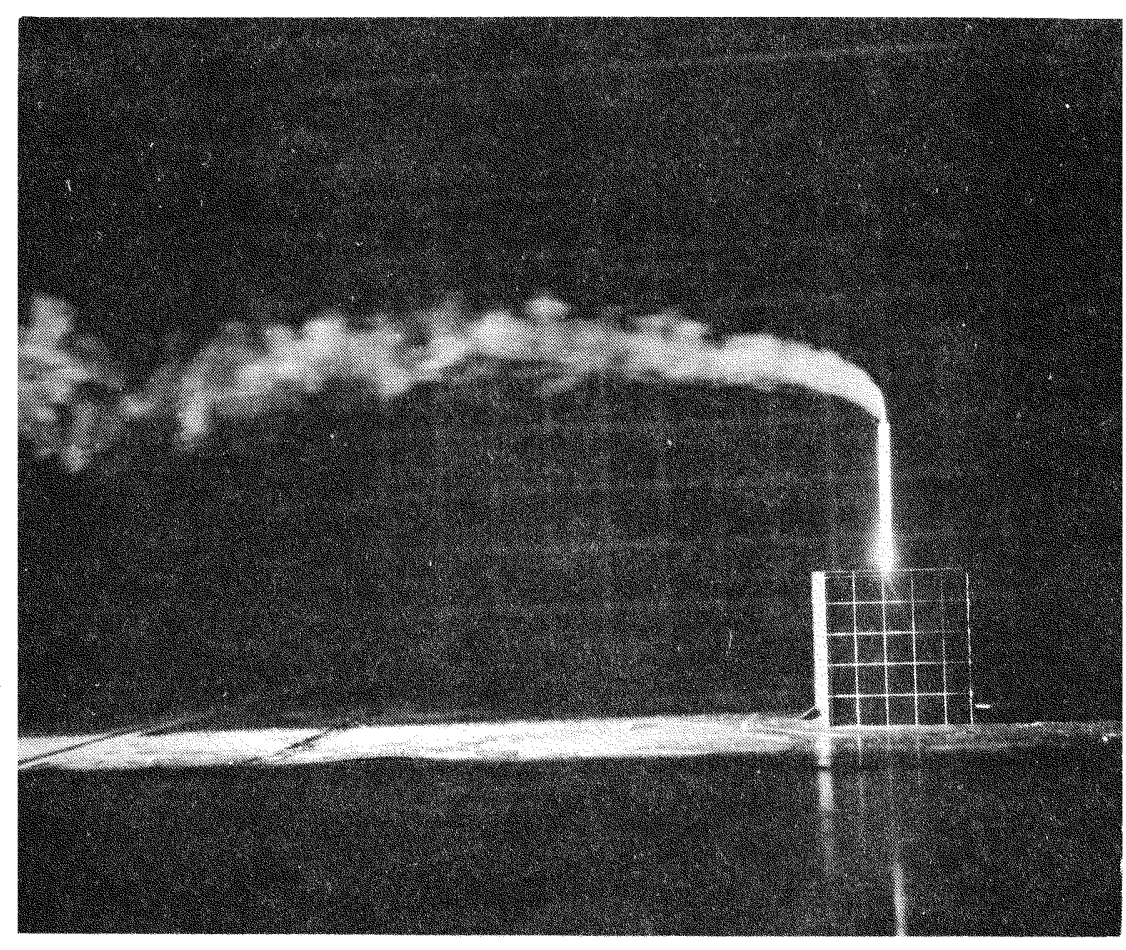

Fig. $16 \quad \mathrm{~h}_{\mathrm{s}} / \mathrm{h}_{\mathrm{b}}=2, \quad \mathrm{~V}_{\mathrm{s}} / \mathrm{V}_{\infty}=2$

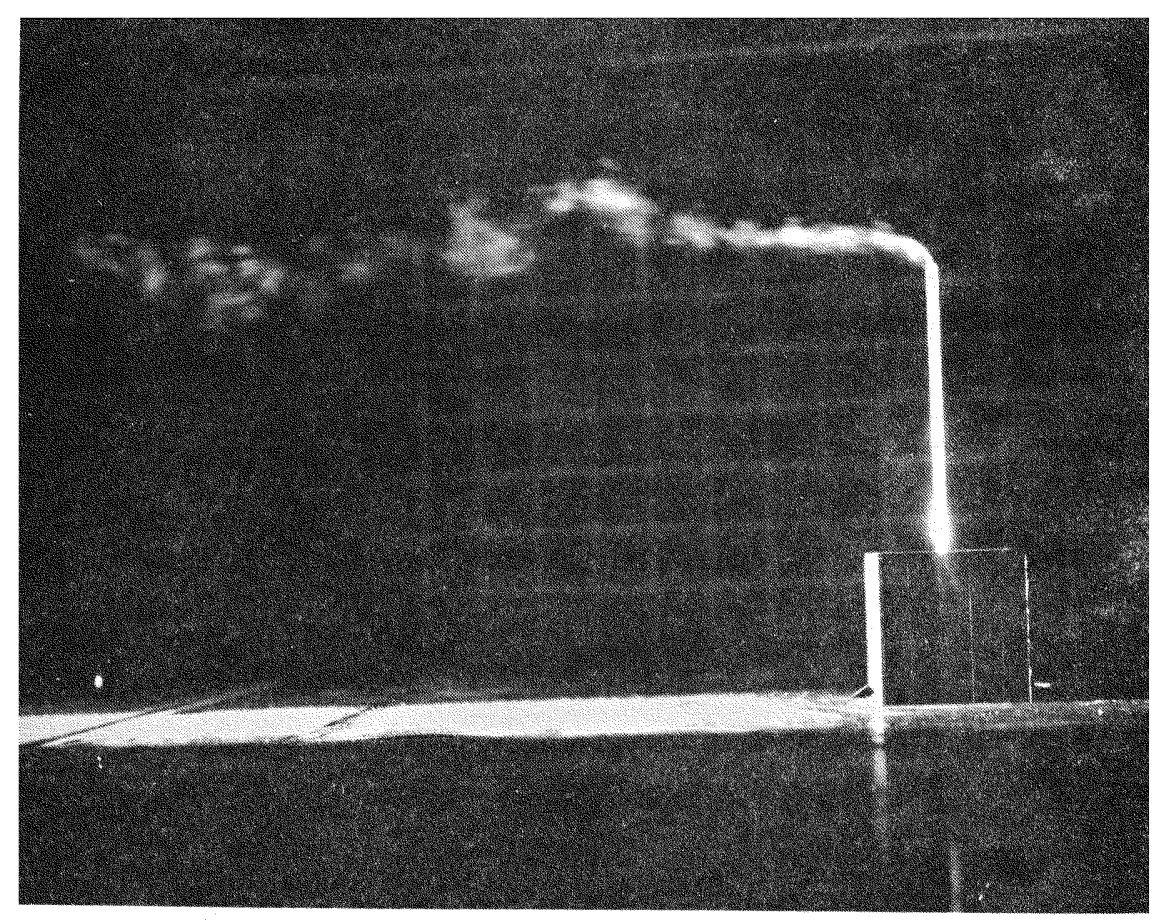

Fig. $17 \quad h_{s} / h_{b}=3, \quad v_{s} / V_{\infty}=1 / 2$ 


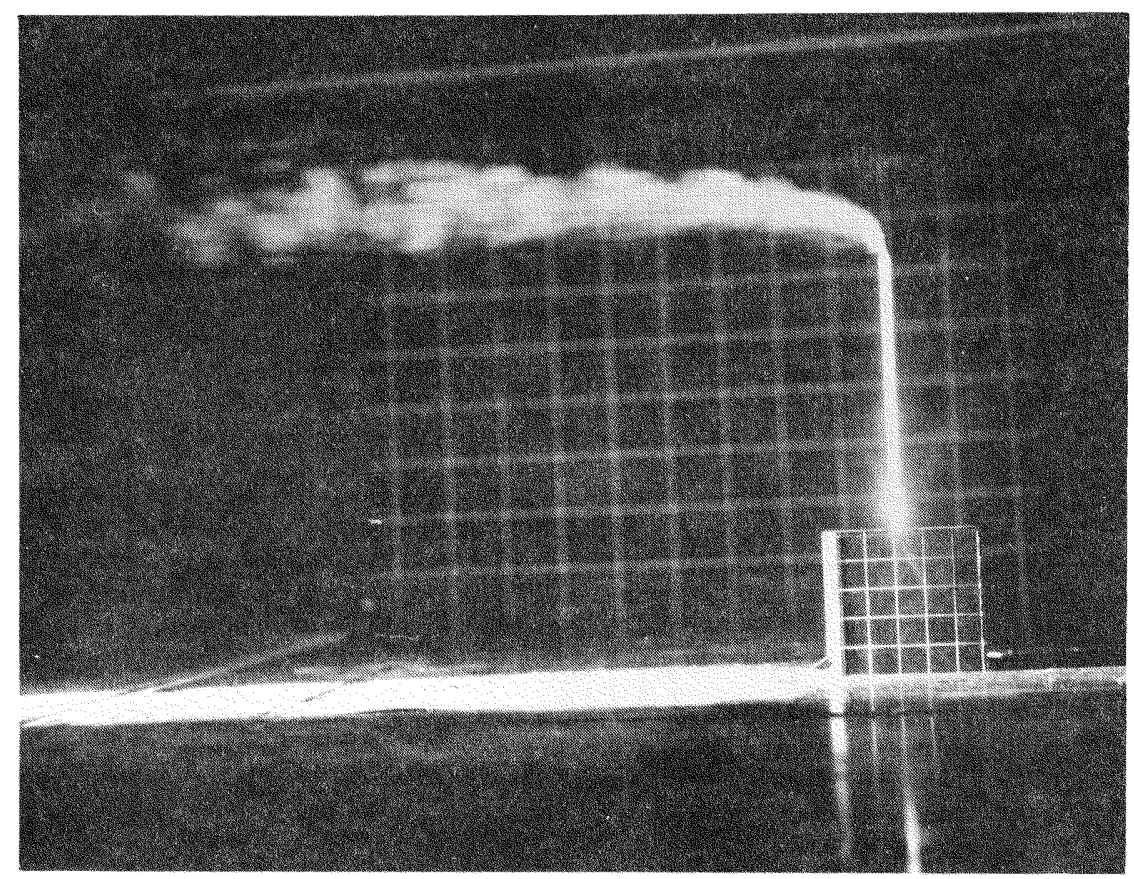

Fig. $18 \quad h_{s} / h_{b}=3, \quad V_{s} / V_{\infty}=1$

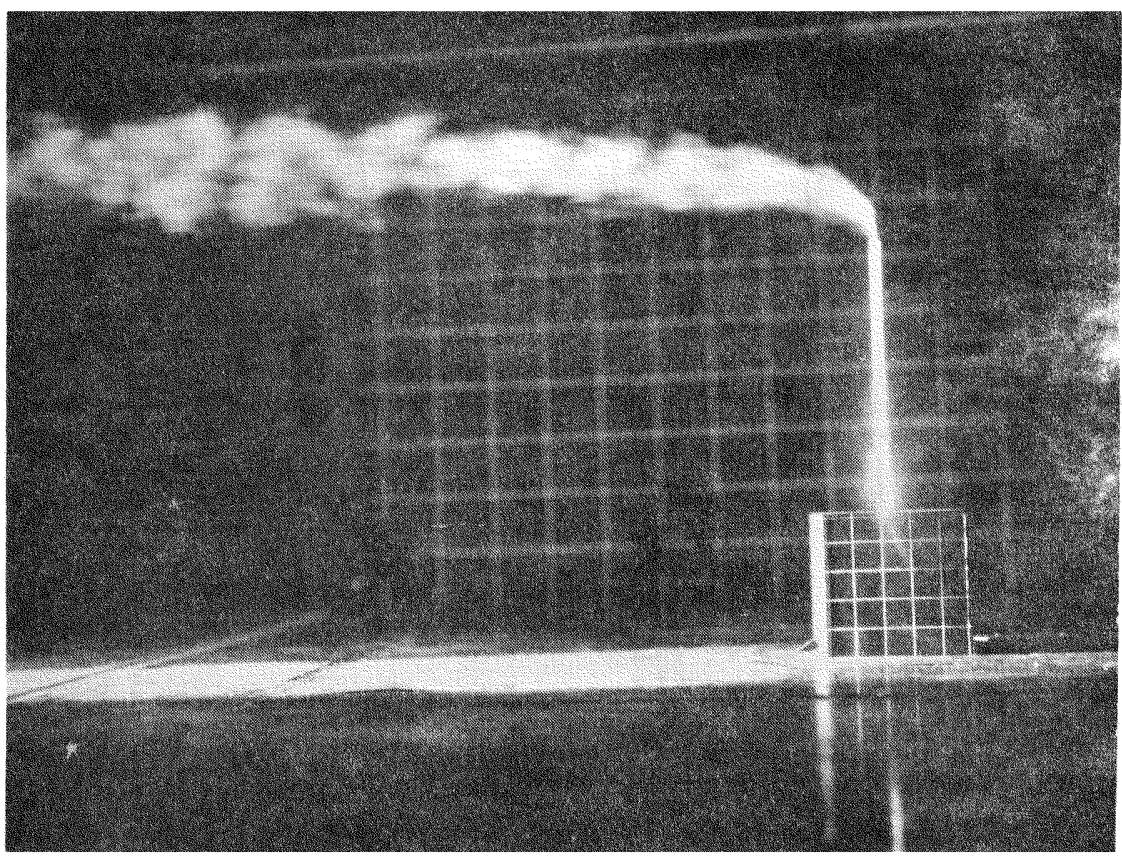

Fig. $19 \quad h_{s} / h_{b}=3, \quad V_{s} / V_{\infty}=2$ 


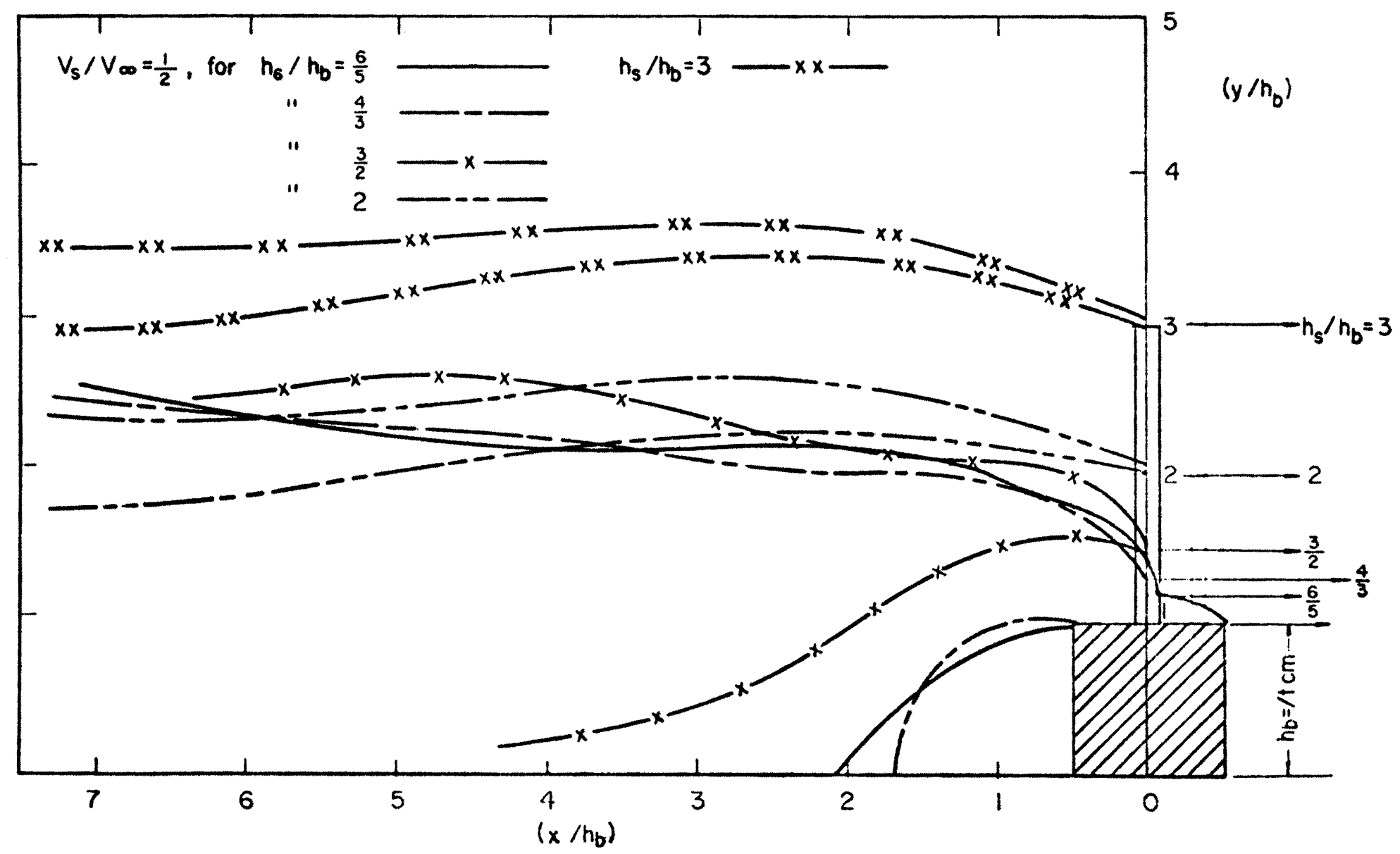

Fig. 20 Visible smoke boundaries for $\mathrm{V}_{\mathrm{s}} / \mathrm{V}_{\infty}=1 / 2$ 


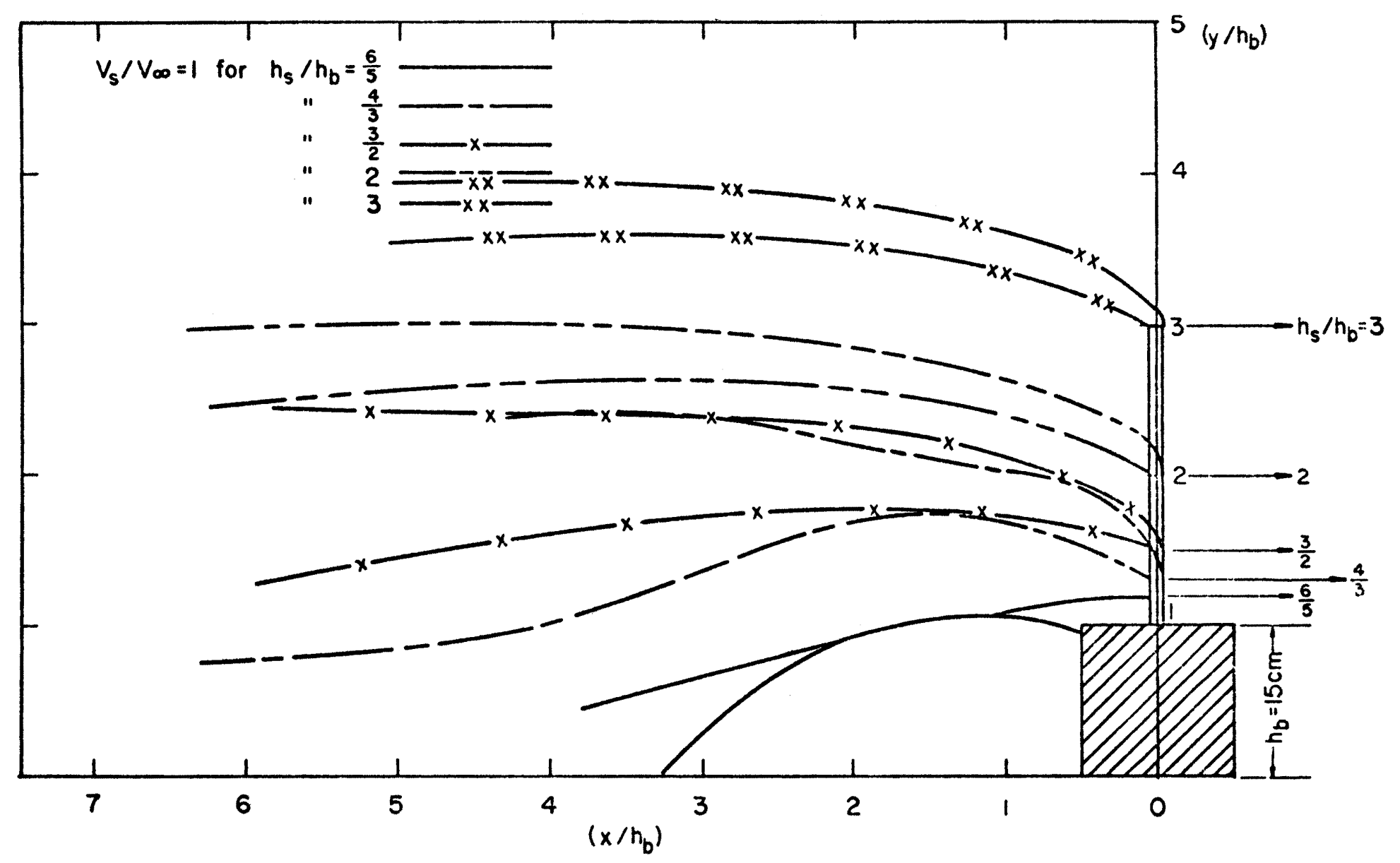

Fig. 21 Visible smoke boundaries for $v_{s} / v_{\infty}=1$ 


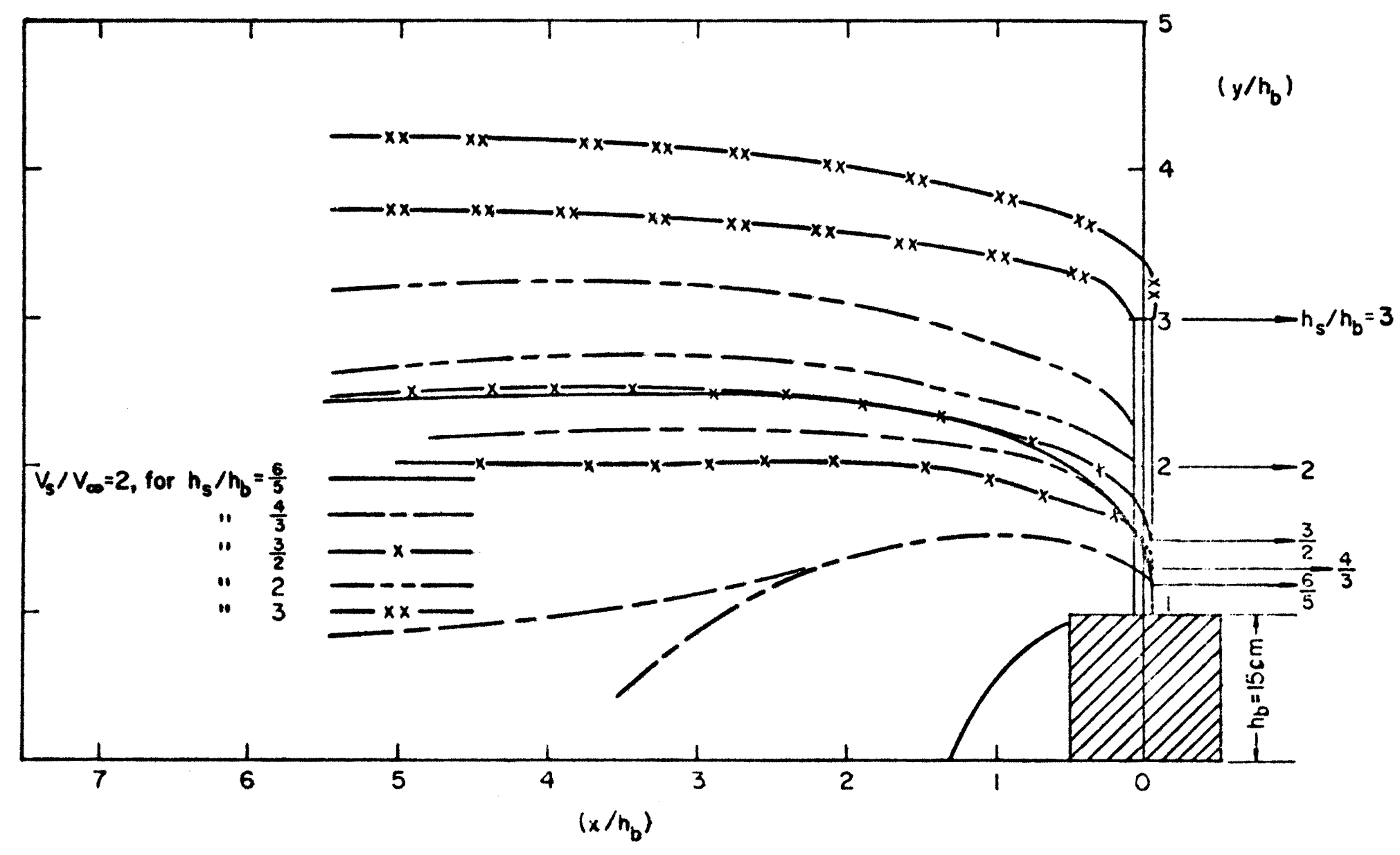

Fig. 22 Visible smoke boundaries $v_{s} / V_{\infty}=2$ 


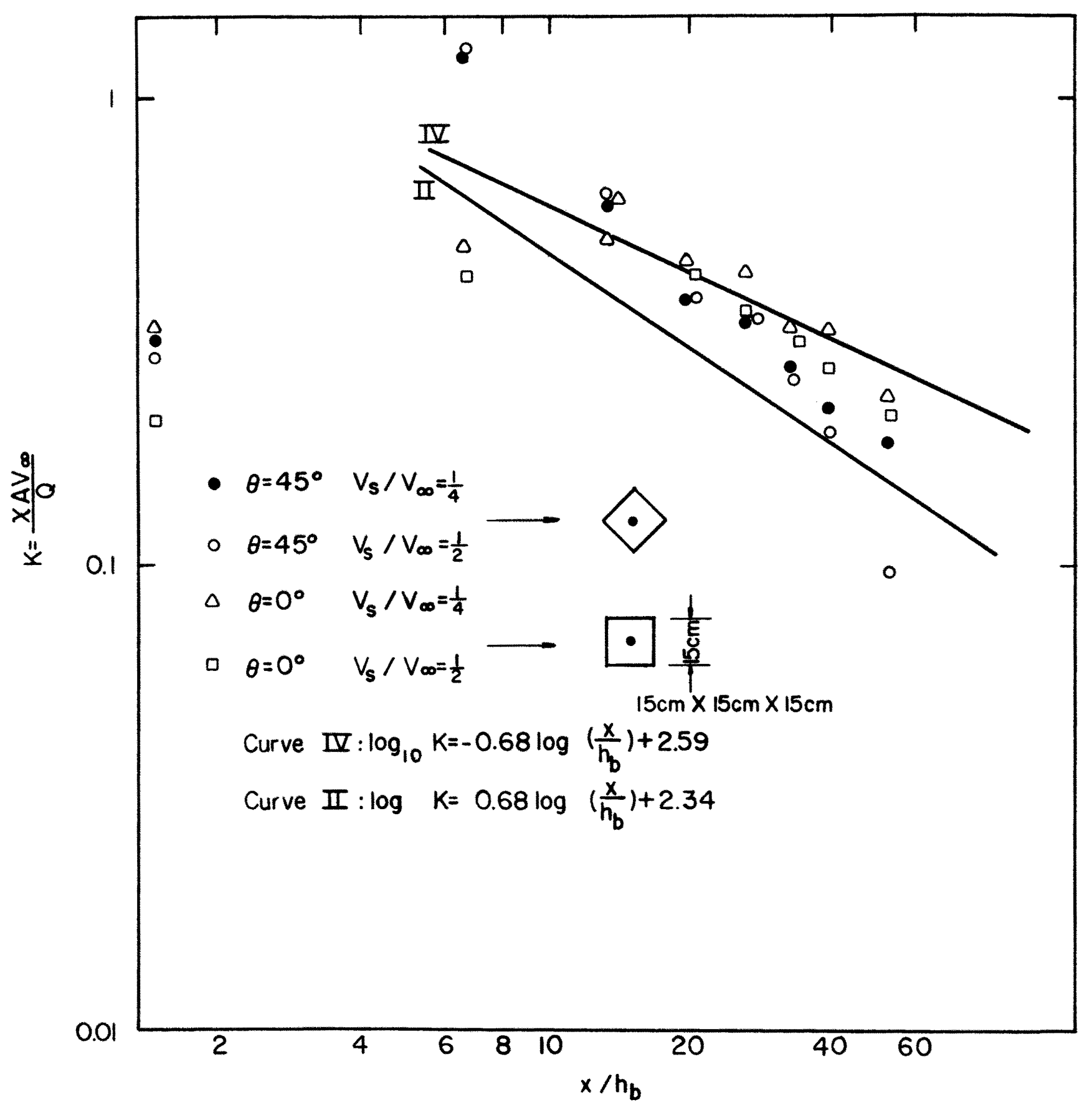

Fig. 23 Ground concentration for zero stack heights for $V_{s} / V_{\infty}=1 / 2,1 / 4$ 


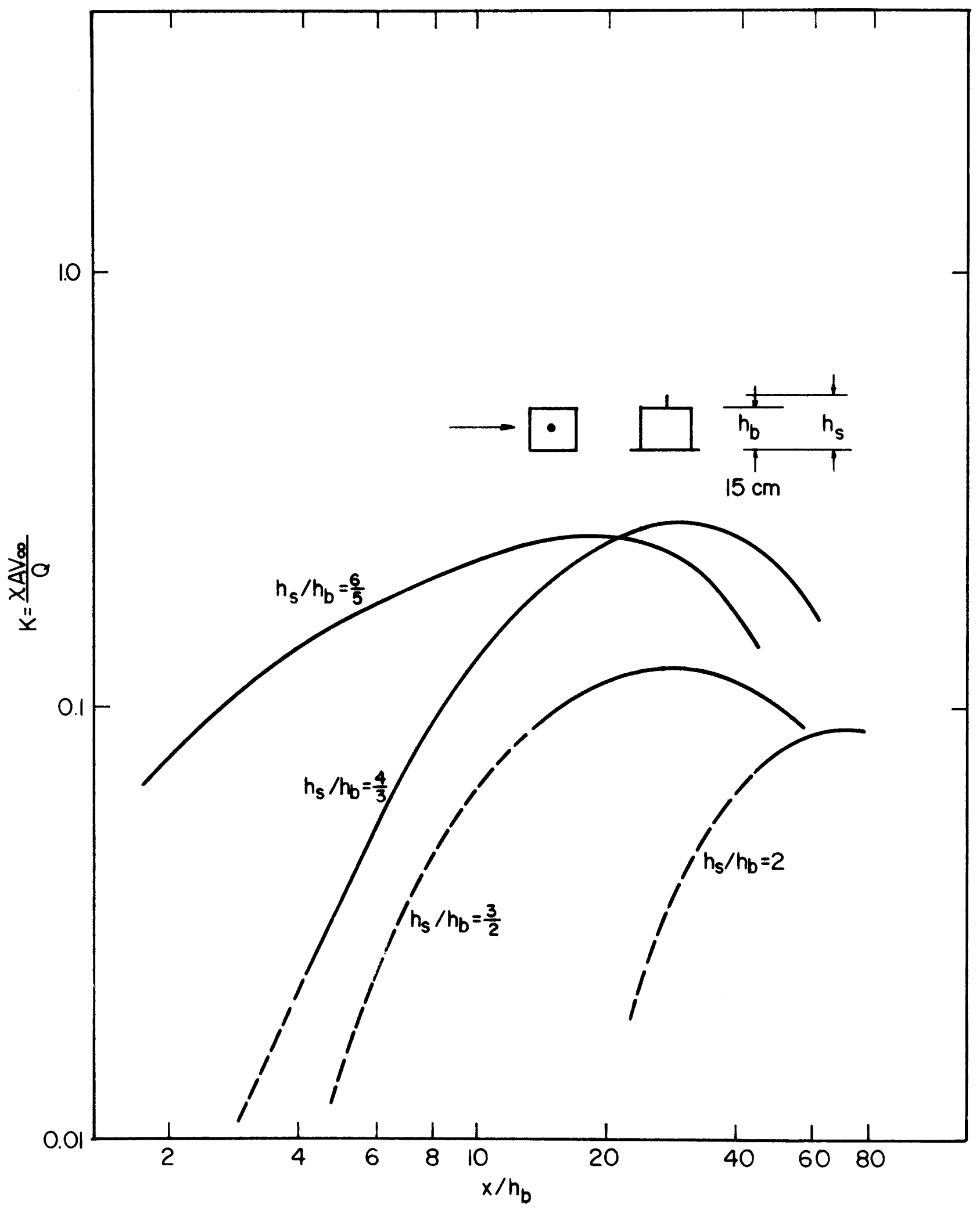

Fig. 24 Ground concentration for $\theta=0^{\circ}, V_{s} / V_{\infty}=1 / 2$, non-zero stack
heights 


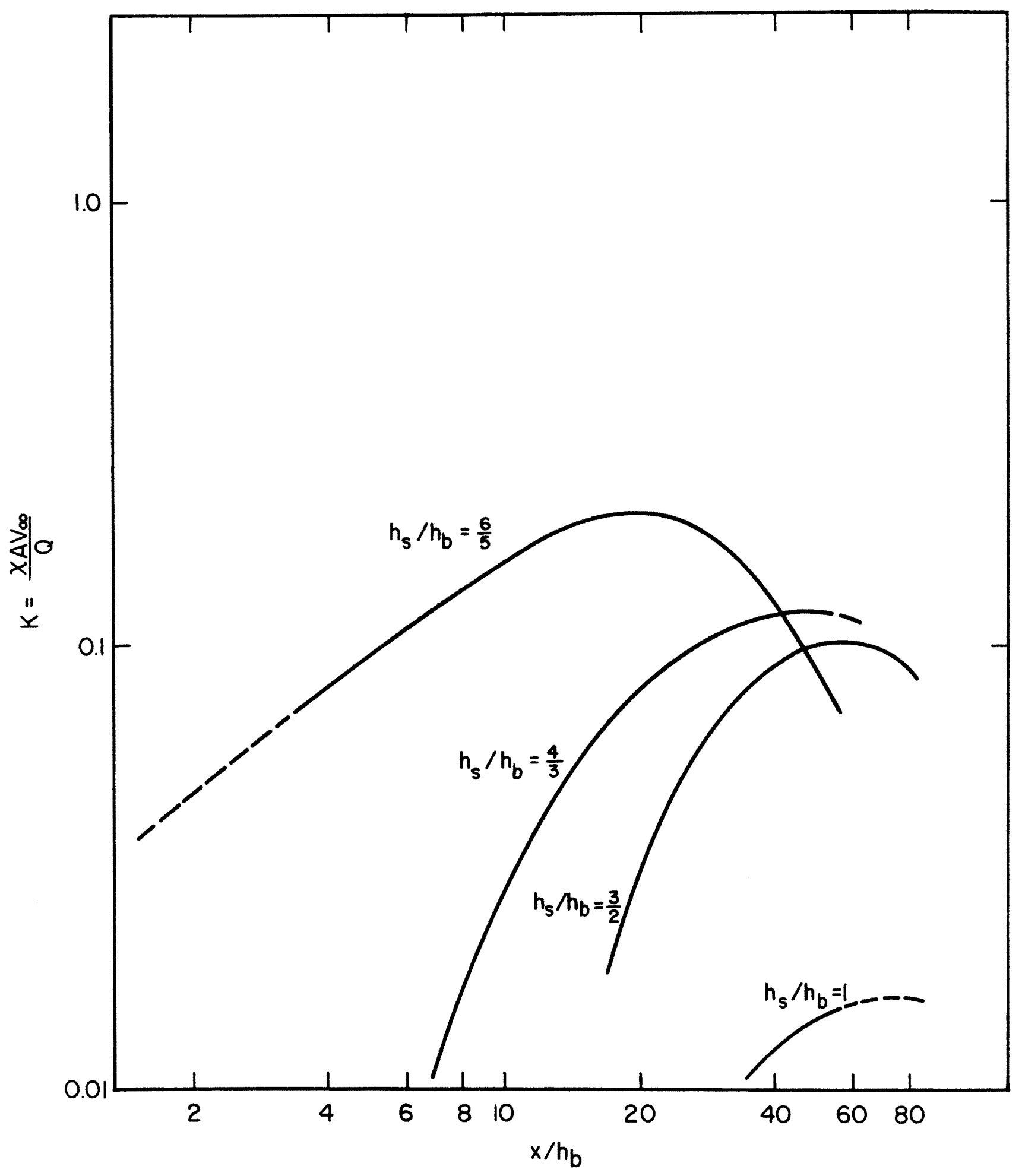

Fig. 25 Ground concentration for $\theta=0^{\circ}, V_{s} / V_{\infty}=1$, non-zero stack
heights 


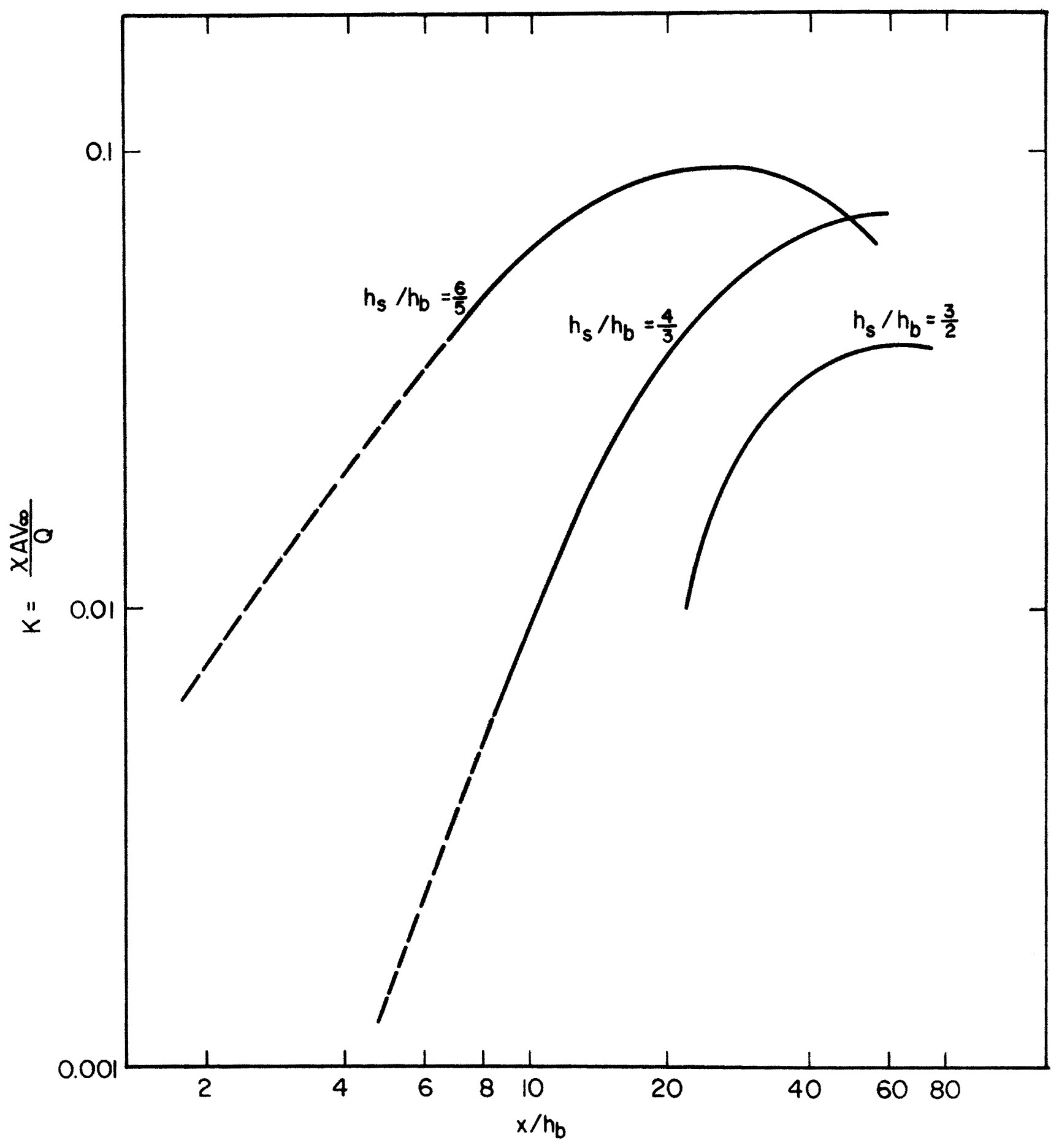

Fig. 26 Ground concentration for $\theta=0^{\circ}, V_{s} / V_{\infty}=2$, non-zero stack heights 


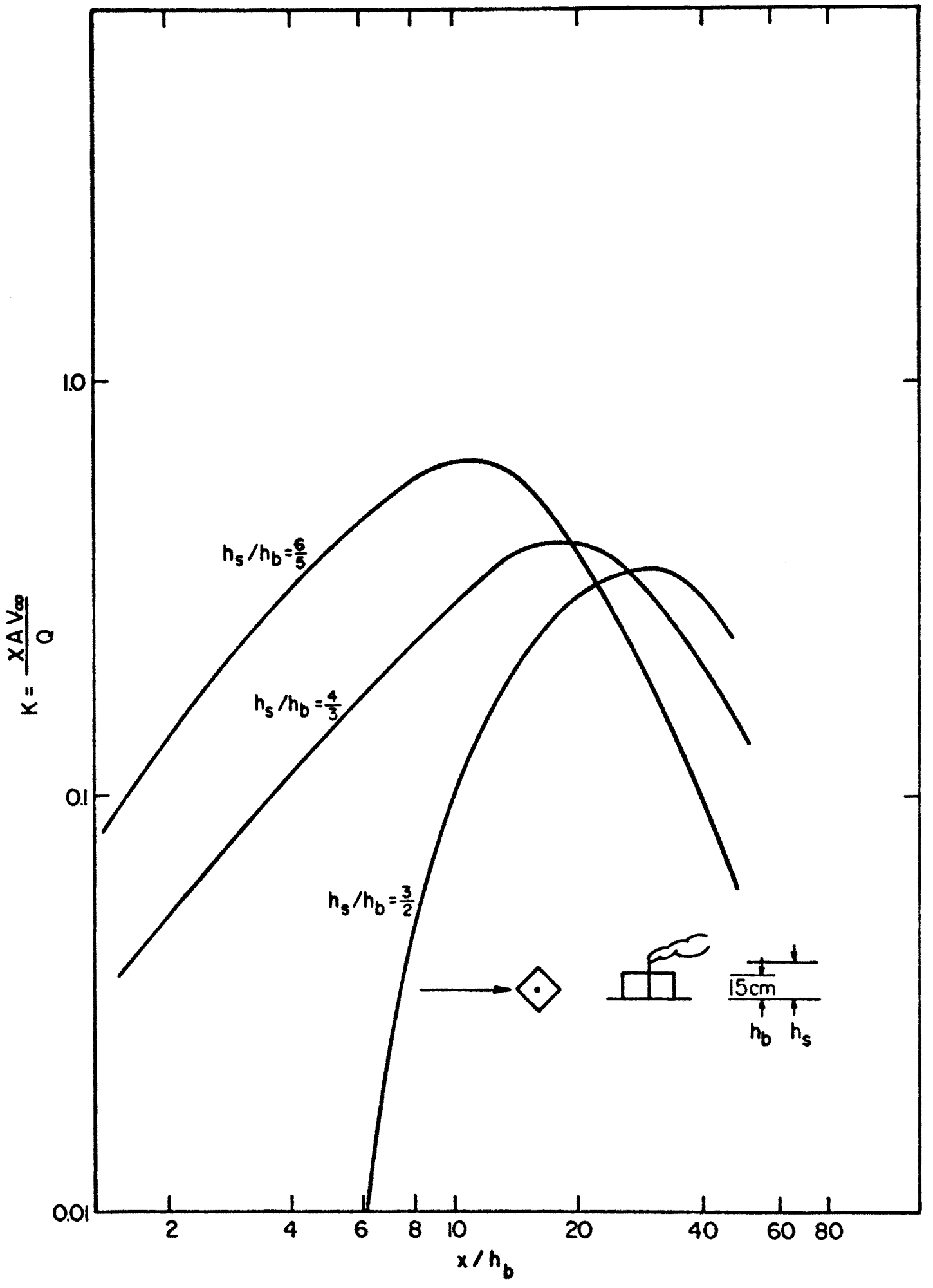

Fig. 27 Ground concentration for $=45^{\circ}, V_{s} / V_{\infty}=1 / 2$, non-zero stack heights 


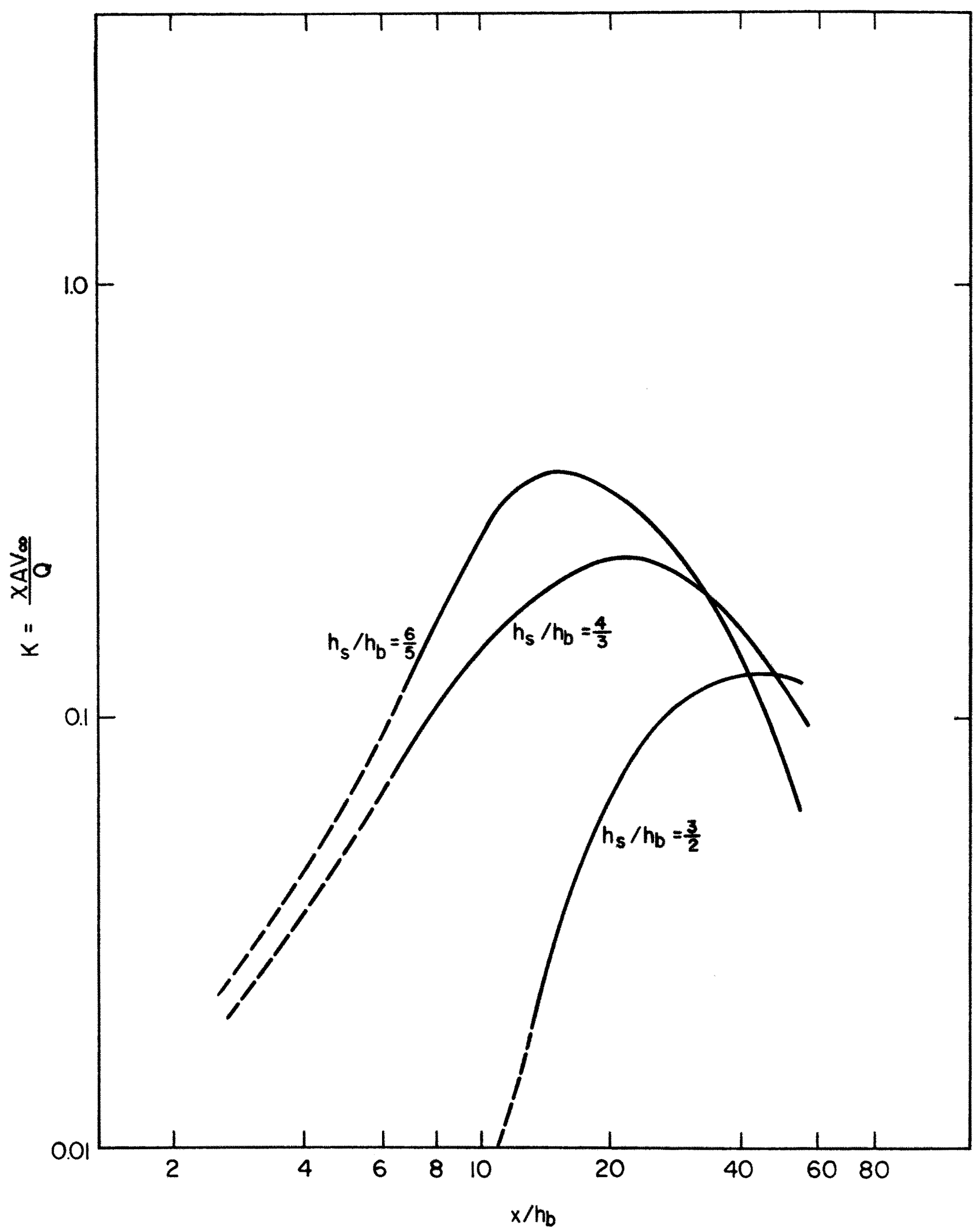

Fig. 28 Ground concentration for $\theta=45^{\circ}, V_{s} / V_{\infty}=1$, non-zero stack
heights 


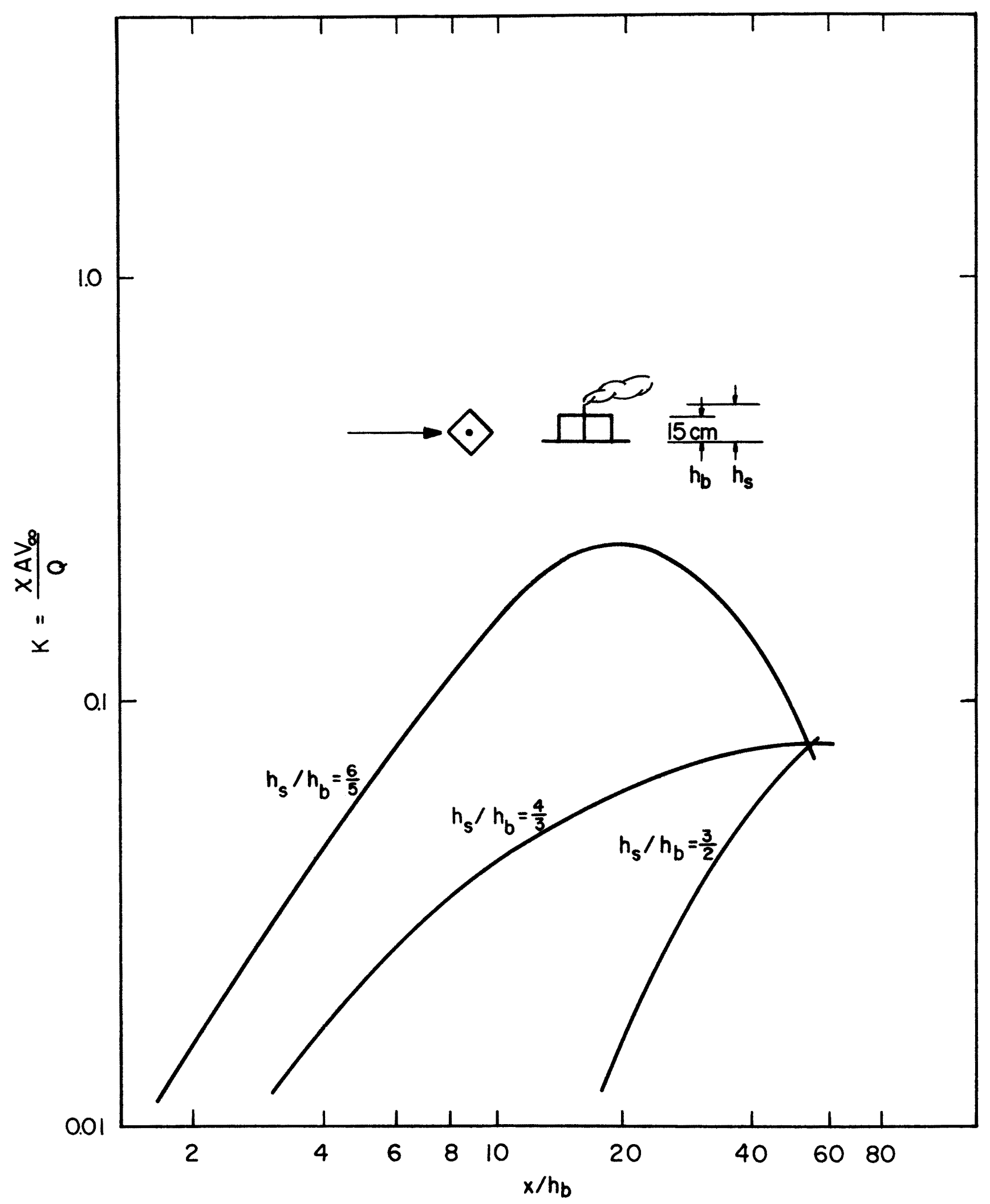
Fig. 29 Ground concentration for $\theta=45^{\circ}, V_{s} / V_{\infty}=2$, non-zero stack
heights 


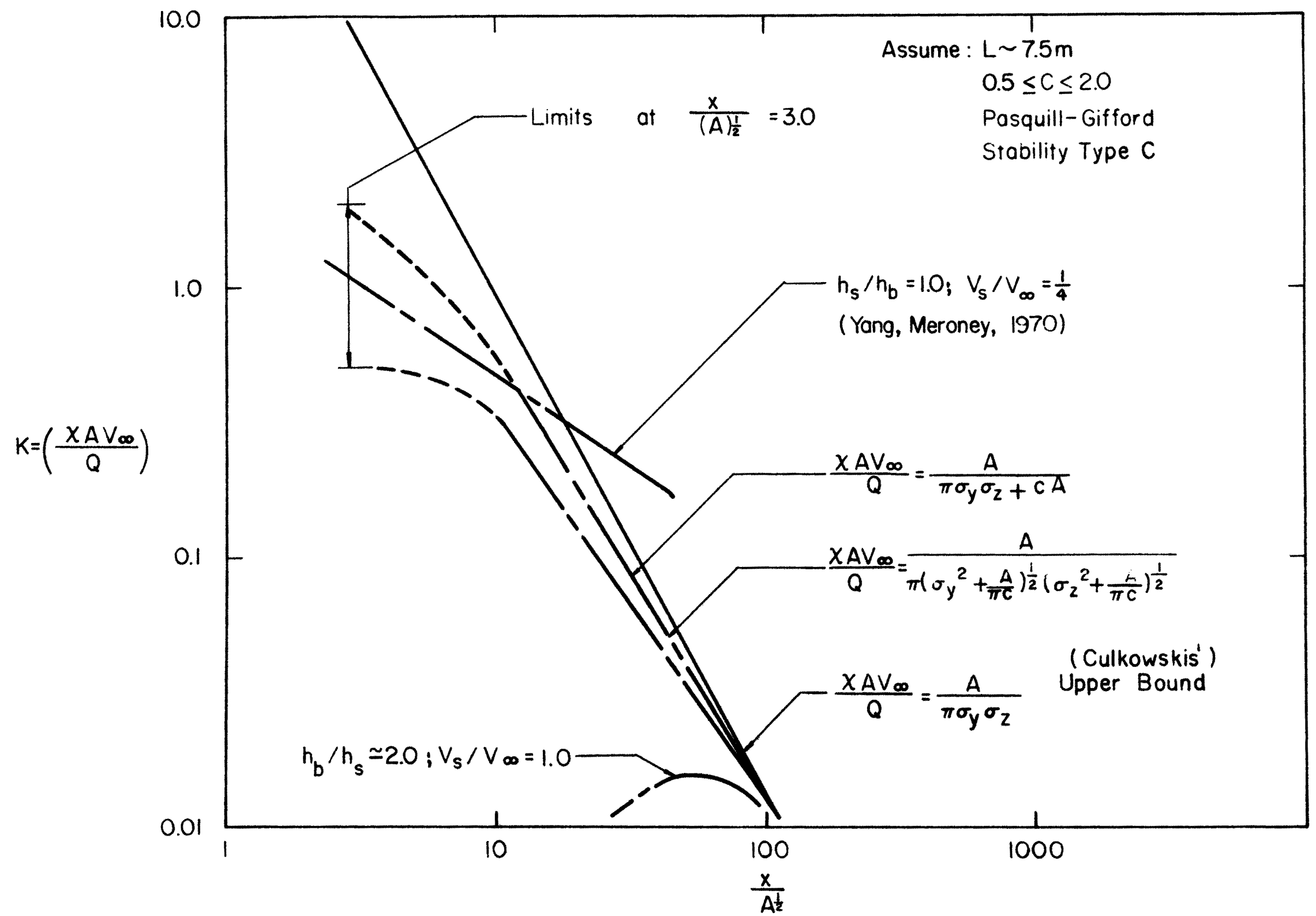

Fig. 30 Various options for entrainment estimation 


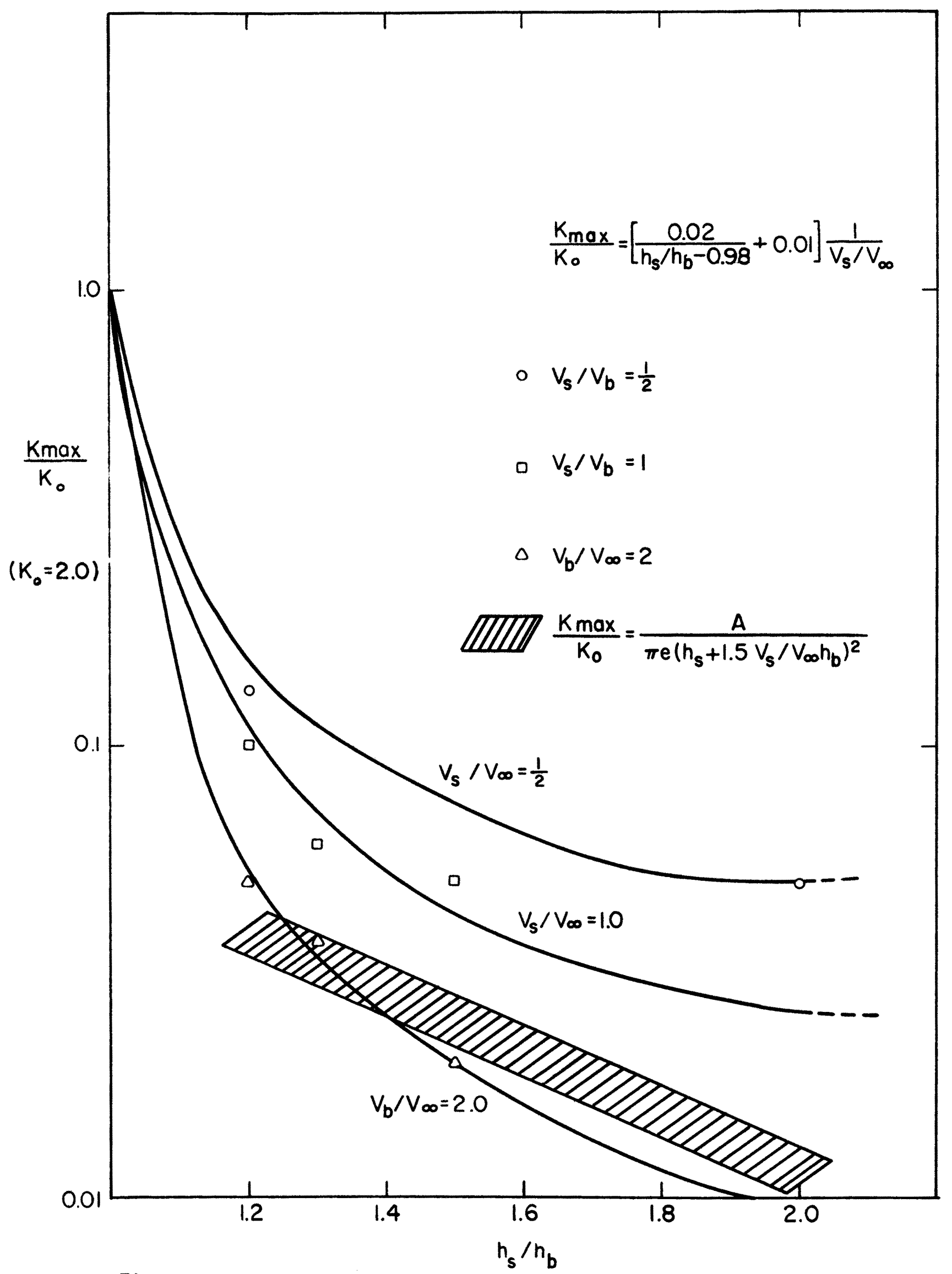

Fig. 31 Dispersion improvement due to increased stack heights and exit velocities 


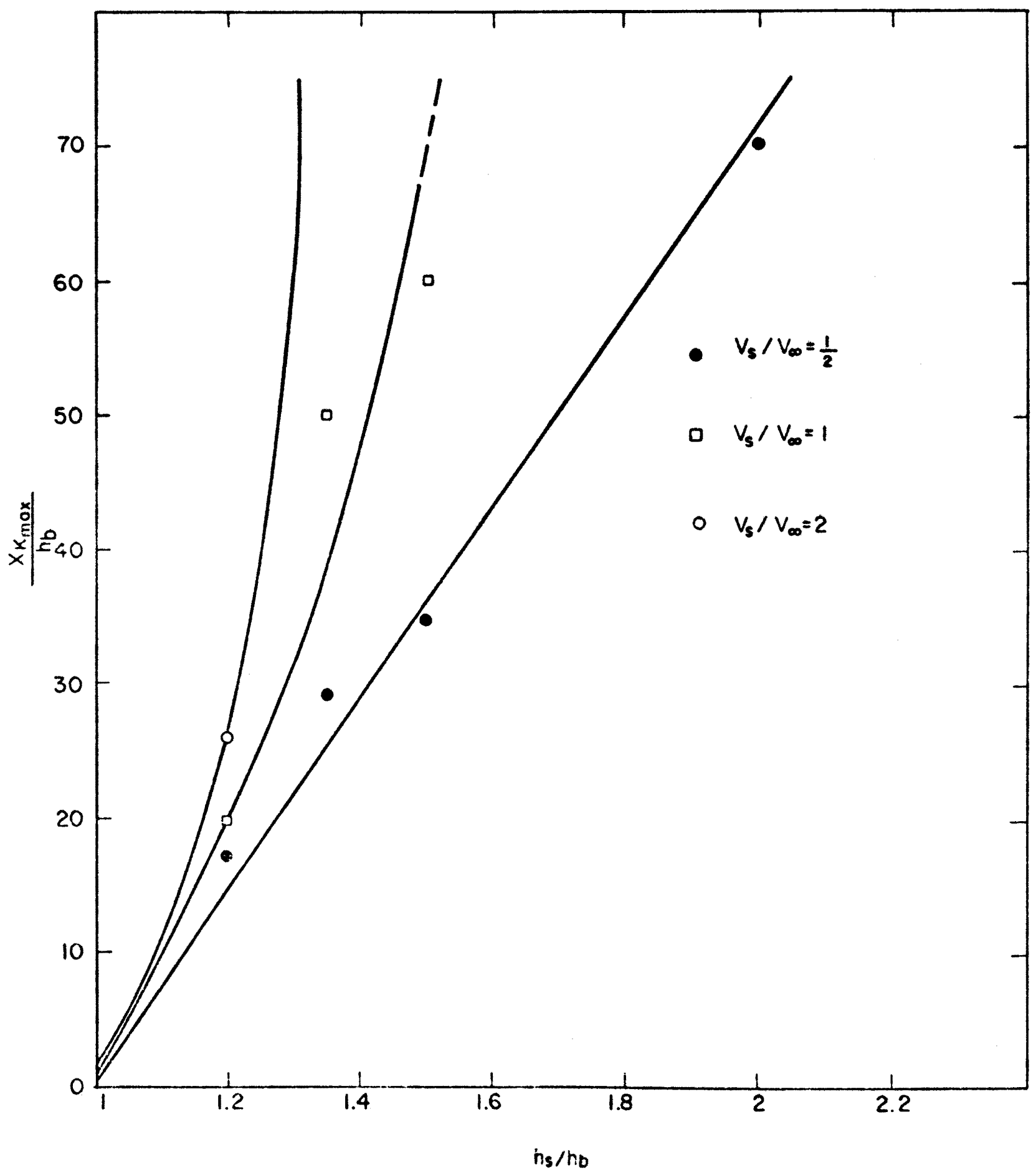

Fig. 32 Distances of maximum concentration for various stack heights
and exit velocities, $\Theta^{\mathrm{O}}=0^{\mathrm{O}}$ 


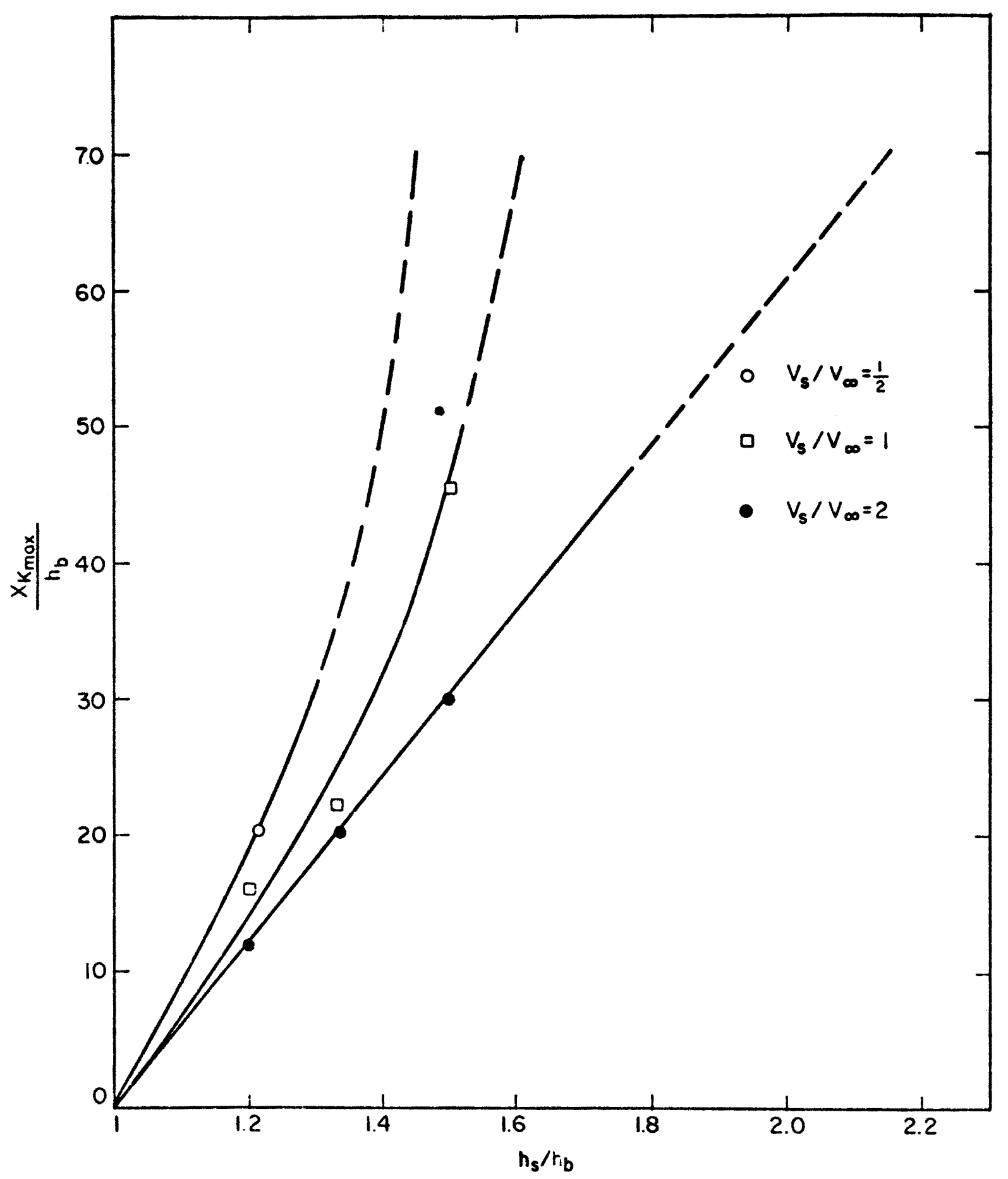

Fig. 33 Distances of maximum concentration for various stack heights and exit velocities $\theta=45^{\circ}$ 
Table A: Conversion of $v_{s} / v_{\infty}$ to $v_{s} / v_{h}$

\begin{tabular}{|c|c|c|c|}
\hline Height & $* V_{h}(\mathrm{~cm} / \mathrm{s} \mathrm{ec})$ & $* * v_{s} / v_{\infty}$ & $v_{s} / v_{h}$ \\
\hline $\begin{array}{l}h_{b}=15^{\mathrm{cm}} \\
\text { ro stack height) }\end{array}$ & 15.6 & $\begin{array}{l}1 / 4 \\
1 / 2\end{array}$ & $\begin{array}{l}0.32 \\
0.64\end{array}$ \\
\hline $\begin{array}{c}\left(\mathrm{h}_{\mathrm{b}}+1 / 5 \mathrm{~h}_{\mathrm{b}}\right) \\
=18^{\mathrm{cm}}\end{array}$ & 16.4 & $\begin{array}{c}1 / 2 \\
1 \\
2\end{array}$ & $\begin{array}{l}0.609 \\
1.21 \\
2.43\end{array}$ \\
\hline $\begin{array}{c}\left(h_{b}+1 / 3 h_{b}\right) \\
=20^{c m}\end{array}$ & 16.6 & $\begin{array}{c}1 / 2 \\
1 \\
2\end{array}$ & $\begin{array}{l}0.602 \\
1.20 \\
2.40\end{array}$ \\
\hline $\begin{array}{c}\left(h_{b}+1 / 2 h_{b}\right) \\
=22.5^{\mathrm{cm}}\end{array}$ & 17.0 & $\begin{array}{c}1 / 2 \\
1 \\
2\end{array}$ & $\begin{array}{l}0.588 \\
1.17 \\
2.35\end{array}$ \\
\hline $\begin{array}{r}\left(h_{b}+h_{b}\right) \\
=30^{c m}\end{array}$ & 18.1 & $\begin{array}{c}1 / 2 \\
1 \\
2\end{array}$ & $\begin{array}{l}0.555 \\
1.11 \\
2.22\end{array}$ \\
\hline $\begin{array}{c}\left(h_{b}+2 h_{b}\right) \\
=45^{c m}\end{array}$ & 19.4 & $\begin{array}{c}1 / 2 \\
1 \\
2\end{array}$ & $\begin{array}{l}0.515 \\
1.03 \\
2.06\end{array}$ \\
\hline
\end{tabular}

${ }^{*} V_{h}$ : Mean local velocity, measured $2^{m}$ from the building (upstream). $* * \mathrm{~V}_{\infty}: 2 \mathrm{~m} / \mathrm{sec}$ 
Table B: Ground Concentration $\left(\frac{\mathrm{L}^{2} \times \mathrm{V}_{\infty}}{\mathrm{Q}}\right) \quad \theta=0^{\circ}$

a. Dimension of the Building: $15^{\mathrm{cm}} \times 15^{\mathrm{cm}} \times 15^{\mathrm{cm}}$

\begin{tabular}{|c|c|c|c|c|c|c|c|c|c|}
\hline$v_{s} / v_{\infty}$ & $h_{s} / h_{b}$ & & & & & & & & \\
\hline & & $1 / 4$ & 1 & 2 & 3 & 4 & 5 & 6 & 8 \\
\hline $1 / 4$ & 0 & . 329 & .491 & .610 & .458 & .418 & .328 & .323 & .233 \\
\hline $1 / 2$ & 0 & .208 & .433 & .501 & .433 & .354 & .311 & .274 & .207 \\
\hline $1 / 2$ & $6 / 5$ & .086 & .156 & .188 & .253 & .226 & .176 & .145 & .134 \\
\hline 1 & $6 / 5$ & .043 & .101 & .187 & .149 & .160 & .142 & .098 & .072 \\
\hline 2 & $6 / 5$ & .007 & .037 & .082 & .086 & .100 & .096 & & .063 \\
\hline $1 / 2$ & $4 / 3$ & $-\cdots$ & .070 & .209 & .196 & .219 & .278 & & .171 \\
\hline 1 & $4 / 3$ & --- & .010 & .043 & .089 & .098 & .104 & & .123 \\
\hline 2 & $4 / 3$ & --- & .004 & .016 & .019 & .059 & .057 & & .075 \\
\hline $1 / 2$ & $3 / 2$ & $-\cdots$ & --- & .087 & .156 & .090 & .130 & & .080 \\
\hline 1 & $3 / 2$ & $\cdots$ & --- & .004 & .030 & .054 & .083 & & .102 \\
\hline 2 & $3 / 2$ & ---- & --- & --- & .004 & .021 & .027 & & .038 \\
\hline $1 / 2$ & 2 & $\cdots$ & $\cdots$ & $-\cdots$ & --- & .033 & .046 & & .088 \\
\hline 1 & 2 & --- & $-\cdots$ & --- & --- & --- & --- & & .015 \\
\hline 2 & 2 & --- & --- & --- & $-\cdots$ & $\cdots-$ & ---- & & .009 \\
\hline $1 / 2$ & 3 & ---- & ---- & --- & $\cdots$ & $-\cdots$ & $-\cdots$ & & .010 \\
\hline 1 & 3 & $\cdots-$ & $-\cdots$ & --- & .003 & .003 & .005 & & .006 \\
\hline 2 & 3 & --- & $-\cdots$ & $-\cdots$ & $-\cdots$ & $\cdots$ & $-\cdots$ & & .002 \\
\hline
\end{tabular}

$\mathrm{L}^{2}: 15^{\mathrm{cm}} \times 15^{\mathrm{cm}}$

$X \quad$ : Local mean concentration

$\mathrm{V}_{\infty}: 2 \mathrm{~m} / \mathrm{sec}$

$Q \quad: \quad\left(x_{s} v_{s} A_{s}\right)$ Source strength

$x_{s}$ : Source concentration

$A_{s}$ : Exit a:ea of the stack

-... : Practıcally zero concentration 
Table C: Ground Concentration $\left(\frac{\mathrm{L}^{2} \times \mathrm{V}_{\infty}}{\mathrm{Q}}\right) \quad \theta=45^{\circ}$ a. Dimension of the Building: $15^{\mathrm{cm}} \times 15^{\mathrm{cm}} \times 15^{\mathrm{cm}}$

\begin{tabular}{|c|c|c|c|c|c|c|c|c|c|}
\hline$I_{s} / v_{\infty}$ & $h_{s} / h_{b}$ & & & & & & & & \\
\hline & & $1 / 4$ & 1 & 2 & 3 & 4 & 5 & 6 & 8 \\
\hline $1 / 4$ & 0 & .315 & 1.238 & .597 & .376 & .333 & .267 & .211 & .180 \\
\hline $1 / 2$ & 0 & .284 & 1.284 & .610 & .376 & .333 & .255 & . 197 & .096 \\
\hline $1 / 2$ & $6 / 5$ & .096 & .522 & .659 & .341 & .222 & .155 & & .053 \\
\hline 1 & $6 / 5$ & .012 & .110 & .379 & .340 & .211 & .142 & & .085 \\
\hline 2 & $6 / 5$ & .016 & .052 & .214 & .212 & .213 & .146 & & .079 \\
\hline $1 / 2$ & $4 / 3$ & .039 & .213 & .458 & .440 & .416 & .235 & & .144 \\
\hline 1 & $4 / 3$ & .036 & .128 & .114 & .234 & .242 & .158 & & .103 \\
\hline 2 & $4 / 3$ & .037 & .042 & .040 & .080 & .089 & .078 & & .082 \\
\hline $1 / 2$ & $3 / 2$ & $\cdots$ & .016 & .242 & .299 & .361 & .293 & & .153 \\
\hline 1 & $3 / 2$ & $\cdots$ & .012 & .017 & .078 & .124 & .146 & & .112 \\
\hline 2 & $3 / 2$ & $\cdots$ & .004 & .004 & .016 & .035 & .058 & & .090 \\
\hline $1 / 2$ & 2 & $-\cdots$ & --- & --- & --- & -..- & $-\cdots$ & & $\cdots$ \\
\hline 1 & 2 & --- & $\cdots$ & $\cdots$ & $-\cdots$ & --- & $\cdots$ & & .004 \\
\hline 2 & 2 & $--\cdot$ & $\cdots$ & $\cdots$ & -..- & -..- & --- & & .002 \\
\hline $1 / 2$ & 3 & $\cdots$ & $-\cdots$ & $-\cdots$ & 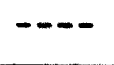 & --- & $\cdots$ & & $\cdots$ \\
\hline 1 & 3 & $-\cdot-$ & $\cdots$ & $\cdots$ & --- & --- & --- & & $\cdots$ \\
\hline 2 & 3 & --- & --- & $\cdots$ & $\cdots$ & --- & --.- & & $-\cdot-$ \\
\hline
\end{tabular}

$\mathrm{L}^{2}: 15^{\mathrm{cm}} \times 15^{\mathrm{cm}}$ 